

\section{CONTENTS}

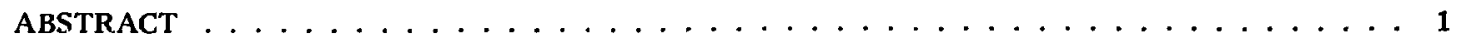

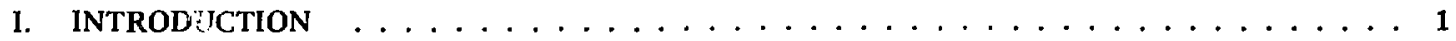

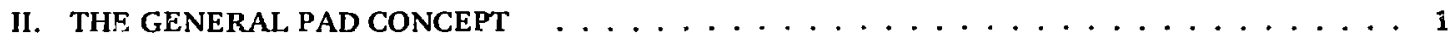

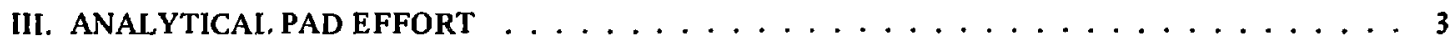

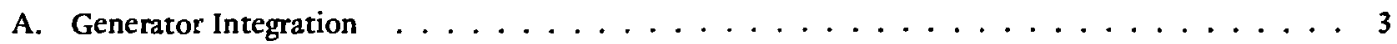

B. Reentry Analysis .............................. 5

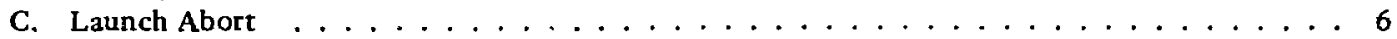

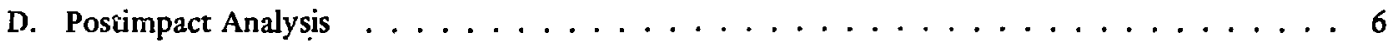

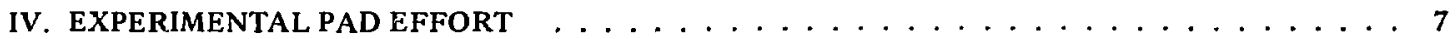

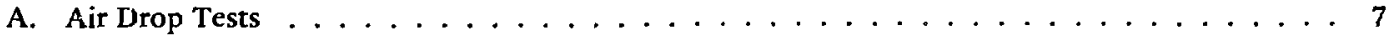
B. Hypersonic Wind Tunnel Testing ...................... 7
C. Impact Testing .............................. 7

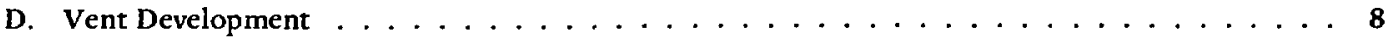

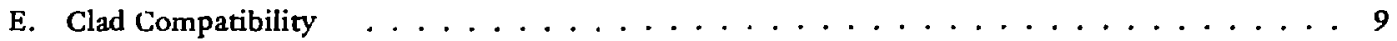

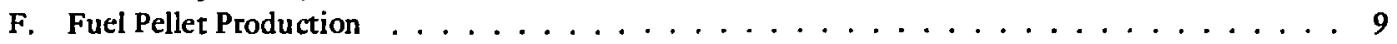
G. Platinum-Iridium Fabrications . . . . . . . . . . . . . . . . . . . . 9

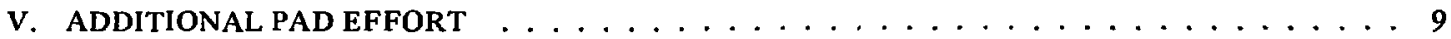

A. Capsule Materials $\ldots \ldots \ldots \ldots \ldots \ldots \ldots \ldots \ldots$

B. Weld Development .............................. 10

C. Vent Development ..............................10

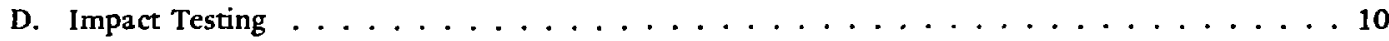

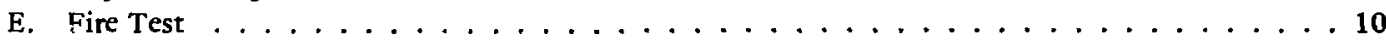

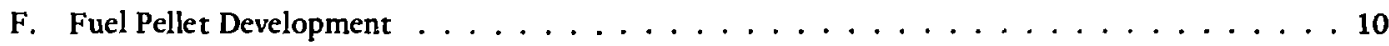

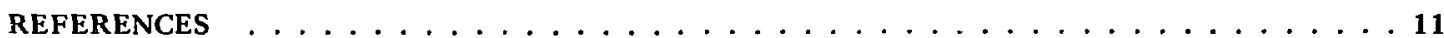

APPENDIX A. PAD FUEL CAPSULE DESIGN SYNTHESIS $\ldots \ldots \ldots$

APPENDIX B. PAD IMPACT TEST COMHONENT DRAWINGS . . . . . . . . . . . . . 23 


\title{
PLUTONIA AERODYNAMIC DISK (PAD) SUMMARY REPORT
}

by

James J. Burns and J. W. Vorreiter

\begin{abstract}
Work on the Plutonia Aerodynamic Disk (PAD) tuel capsule concept began at the Los Alamos Scientific Laboratory the summer of 1971. This work was performed in cooperation with NASA's Ames Research Center and the NUS Corporation. Our objective is to develop a modular heat source for radioisotope thermoelectric generators (RTGs), with primary consideration for nuclear safety.

Analytical effort has been directed to areas such as generator integration, launch abort, reentry, and postimpact. Experimental efforts have included air drop, hypersonic wind tunnel, and impact testing. Progtess was also made in vent development, clad compatibility, and fuel processing. Results are summarized in this report, particularly because the results identify basic fuel capsule characteristics that are desirable from a safety standpoint. Recommendations for future efforts are also included.
\end{abstract}

\section{INTRODUCTION}

This report outlines the status of the Plutonia Aerodynamic Disk (PAD) development work as of October 1, 1973. Burns et al. ${ }^{1}$ published a detailed safety feasibility study of a PAD design sized specifically for use in the Multi-Hundred Watt (MHW) Radioisotope Thermoelectric Generator (RTG). The material covered in Ref. 1 is summarized here as is other more generalized material that has resulted from the PAD development effort.

The PAD concept is more a general approach to fuel capsule design than it is to a specific set of dimensions or hardware configuration. This general approach is described in Sec. II. In Secs. III and IV we summarize the status of various analytical and experimental investigations of the general PAD design approach. Section $V$ covers the efforts that remain to be completed.

\section{THE GENERAL PAD CONCEPT}

The PAD fuel capsule evolves from a consideration of the various accident environments that may result in release of nuclear fuel from the capsule. Nume ous configurations were considered during the PAD study. At its present state of development, the preferred PAD cc nfiguration is as shown in Fig. 1.

Plutonium was considered in all areas of the PAD study. In some instances, curium was also considered. The fuel pellets were studied in both cylindrical and spherical shapes, but in all cases the pellets were small $(\sim 15 \mathrm{~W})$. Figure $\mathrm{i}$ shows $15-\mathrm{W}$ spherical plutonium fuel pellets. Presently, the spherical pellet seems to be the best choice based on superior impact survivability.

Each fuel pellet is encapsulated in a single 0.020 -in.thit:k vented metal clad. Various noble metals 


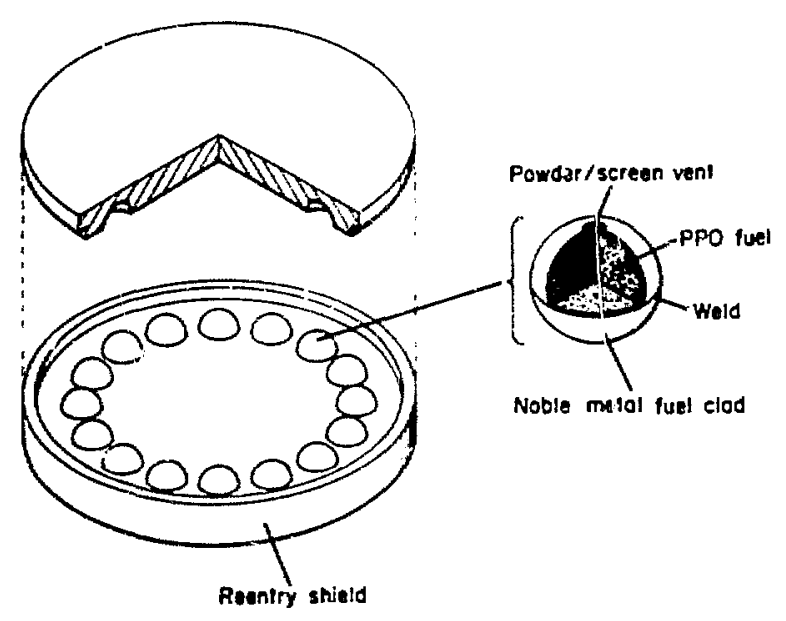

Fig. $i$.

PAD reference design.

and noble meol alloys were considered. The Oak Ridge National Laboratory (ORNL) Pt/Rh/W alloy appears to be accepable. Iridium should also be acceptable, but not required, and its low-temperature impact characteristics have not been determised. In many cases PU2S it was considered, mainly because of its availability at the Los Alamos Scientific Laboratony (LASL) for experimental uses. All of these materials and other noble metals and noble metal atloys have essentially the same densities and thermal charaeteristies allowing them to be considered interchangeably in most PAD analytical studies. Although the ORNL PU/Rh/W alloy now scems to be the best candidatc, the ultimate material selection for the elad must await demonstration of compatibility with the other materials in the system and final definition of generator operating temperature requirements. The clad vent is fabricazed from a combination of elad material scteen and powder, as described in Sec. IV.D.

Figure 1 shows 16 fuel pellets (240 W). PAD studies lave covered fuel capsule inventorics from 45 to $300 \mathrm{~W}$. An optimum inventory has not been found, but it appears that the inventory ean be varied as desired to best integrate the fuel eapsule with the generator or, possibly, to improve the postimpact recovery situation.

The encapsulazed fuel pellets in Fig. 1 are embedded directly inso the graphite reentry heat shield. In many of the PAD amalyrical studies, the fuel pellets were embedded into a single large strength member. llowever. subsequent impact teses indieated that this strength membet wiss unnecessary. The use of a strength member also adds another material to the compatibitity test matrix and another gap to the heat source, thus raising its operating temperature gradient. The strength member also increased the PAD's weight, impact velocity, and reentry heating rate.

Many different graphites were considered for the reentry heat shield, including molded graphites such as POCO and ATy, no-dimensional composites such as Carbitex, and three-dimensional composites such as Avco's MOD 3. All appear to be acceptable, with MOD 3 the best. Tests indicate that the two-dimensional composize considerably increases the survivable impact velocity over the use of molded graphites. Therefore. the preferred niaterial for the recnery shicld of Fig. 1 is a composite graphite.

We cannot be more specific about the PAD configuration is to dimensions, weighes, ctc., without integrating the heat source to a specific generator. However, the PAD can be described as having certain additional characteristics as follows.

Low Ballistit Coefficient-A low ballistic cocfficient $\left(W / C_{D} A\right)$ results in many desirable feztures. First, reentry heating depends directly on the ballistic cuefficient. Thus, a low ballistic coeffieient generally will lead to lower capsule component temperatures during reentry. A low ballistic coefficient is not the only way to assure reentry survival, but the other available methods have undesirable side effects. For example, a fuel capsule with large thermal capacitance can absorb high heating rates without excessive component temperatures. Hlowever, such systems hase high terminal velocities making impact survival more difficule, and they are plagued by thermal stress problems. Another method involves the use of insu. iarion that will cause high surface temperatutes on the capsule during reentry. The high surface temperatures in turn result in high energy losses by either retadiation or ablation. However, in most systems this method tesults in high steady-state component temperalures that intcnsify long.term materials problems that are quite sensitive es temperature. PAD can benefit from the use of additional resenty insulation when the reentry heat now path is different from the secady-state heat flow path. but addiwonal insulation for reentry protection sill probably not be tequired if the ballistic enefficient is low.

The stcond important result of low ballistic corfficient is low teminal velocity. Appendix G of Ref. 1 shows the dependeny of tetminal relocity on ballistie cocffictene. Tests indicate that bare. single pellet capsules sutrive intact at impact selocities of -150 feisec or less on stecl targets. The use of an eneny absothing maprial around the fuet may also assure impact surrival; howeter, at this time this technology is without sufficicnt analytical or cxperimental basis to permit accutate trade off apainst other system requiremenes. Presently, it appoars that the 
low impact velocity that results from a low ballistic coefficient is the best way to assure impact survival.

PAD designs having ballistic coefficients between 2 and $10 \mathrm{lb} / \mathrm{ft}^{2}$ appear to be sufficiently low to attain the above desirable results. Values between 10 and $20 \mathrm{lb} / \mathrm{ft}^{2}$ are marginal.

Limited Fue: Dimensions-The source of numerous fuel problems can be traced to the fuel dimensions. For instance, the rates of undesirable chemical reactions increase with temperature. In turn, the maximum fuel temperature is dependent on the square of the duel dimensions. Further, fuel fabricators found that fuel cracking can be minimized and dimensional stability and production yield improved by reducing fuel dimensions.

Although analysts will disagree on postimpact thermal modeling, they agree that reducing the number of warts of fucl per unit area of container will result in a lower postimpact temperature. This can be acconplished by a change in configuration (i.e., sphere to cylinder) or a reduction in dimensions. The wattage contained in a sphere is proportional to the diameter cubed (volum:). whereas the surface area of the sphere is proportional to its diameter to the second power. Thus, the surface flux (watts per unit area) of the cepsule can be reduced by decreasing the sphere's diametcr. Thus, a PAD will have relatively small fucl dimensions with a surface area as large as possible.

Regazdless of the capsule designer's efforts to protect the fuel, it is possible to postulate a set of circumstances that will breach the fucl container. If all fuel capsule coneepts are cosnpared on the basis that a breach has occurred, the container with the least amount of fuel will be superior, assuming all other things (i.c., probabilities) are equal.

This advantage is particularly apparent when the launch pad abort environment is ennsidered. Here, both the size and the velocity of potential blast fragments are uncertain and critical for a single contziner fuel capsuie. If the fuet is divided into many conezinets, the exact characteristics of the frapments become less important because one can rely on the low probability of the fragments impacting moze than a fow of the contziners.

Also. for a solid propellant fire, standard practice is to investigate enalytically and experimentally the capsule's response to the credible worst case situation where few if any capsules cas sintive. Again, one can zely on the low probability of morc than a few containers in a unultiple contajner system being breached in this worst case envitonnsent.

Postreentry tecriven is also eritical to the cennsideration of a multiple container BAD system. licre there is no standatd model that casi be tused to compare barious systems. The area of possible impact that must be searched following an orbital decay reentry of any system is usually extremely lange. The area of actual impact of a multiple container fuel capsule system is much smaller by orders of magnitude. The area of actual impact of a single container system is the smallest. From this perspective the larger actual impact area of a PAD system is an advantage permitting rapid concentration of the search force because its footprint should be easier to find. The only time the langer PAD impact area could be a disadvantage is when the circumstances of the reentry are such as to permit accurate prediction of the impact of a single container system in an area smaller than the PAD footprint. Another possible disadvantage might exist if all PADs do not release from the generator at approximately the same time during reentry. The RTG design must provide against this event.

Another PAD disadvantage may exist if a large single container system could be designed to assure impact survival. Here the lange inventory of the single container system may make it much easier to detect. No analysis has been done in this area. However, this could only be considered a disadvantage if the large single container system had the sime probability of impact survival as the PAD.

In addition to the system's operational and safety advantages to be realized by using fuel in small modular packages, developmental and safery qualification testing is facilitated. If the modules are small enougii so permit safe handling in the laboratory or available test faciities, realistic tests, close to the actual environments, can be conducted with live fuel instead of simulants. Thus, full-scale compatibility or impact tests can be conducted readily and real system response defined so that improvements can be directed from a knowledge of actual system performance. This should result in a better design and will promote increased confidence in the necessary safery analysis.

\section{JII. ANALYTICAL PAD EFFOR'T}

\section{A. Gencrator Integration}

Considerable analytical efforr has been directed toward tetermining the adaptability of PAD fuel capsules to various generator designs. The basic modular building block has been a 15-W fuel pellet encapsulated in a vented noble metal container 0.02 to 0.03 in. thick. Designs incorpotating various quantities of these encapsulated pellets cmbedded in graphite heat shiclds (MOD 3 or pO(O) with and without strength members were 
analyzed. While other areas of PAD experimental effort are determining optimum fuel geometry and the need for a strength member, the analytical effort has progressed in a manner that is felt to be generic to the complete range of possibilities. Thus, if impact testing indicated that spherical fuel geometry is superior to cylindrical fuel geometry, or that a strength member was not required, the conclusions of the analytical effort would not change significartly, although the detailed anaiysis might change considerably.

Further, the exact specification of the fuel clad material should not significantly change the conclusions within certain limits. The PAD's low impact temperature requires a clad material that is ductile at temperatures slightly above ambient. Most noble metals and their alloys (Pt/Ir, $\mathrm{Pt} / \mathrm{Rh}, \mathrm{Pt} / \mathrm{Rh} / \mathrm{W}$ ) have essentially the same thermal properties and densities making them analytically interchangeable. Therefore, the exact specification of the clad material can await completion of lengthy fuel compatibility testing.

Heat sources have been dimensionally sized for MHW, Pioneer, Transit, and HPG generators. No thermal or dimensional ircompatibilities were found, but there were significant safety advantages. For the Pioneer and HPG generators, we found that the PAD safety characteristics conld be substantially improved by changing the generator from a 6- to a 10-sided unit. This reduced the PAD's ballistic coefficients for these generators below the marginal value of 10 .

In all cases the PAD had both weight and steady-state thermal advantages over other fuel capsule designs. For these studies, a helium management system was not designed, thus its weight could not be included. A typi:al steady-state thermal distribution is shown in Fig. 2, which was taken from Ref. 1. Figure 2 shows that the temperature gradients in a PAD heat source are relatively low. The basic reasons for this are the small fuel dimensions, low internal capsule heat fluxes, reduced number of gaps, and the small dimensions for materials between the fuel and the thermoelectrics since reentry and impact protection requirements are minimal. Additional reentry and launch pad fire insulation on the flat faces of the PAD would not significantly affect the steady-state temperatures shown in Fig. 2. Also, the loss of helium in the heat source gaps does not affect the distribution as much as in other systems because the number of gaps have been minimized and the heat flux across the gaps is smaller. For the model in Fig. 2, the helium loss in the gaps between the fuel clad and the PAD surface about doubles the temperature gradicnt. The reduced temperature gradients in a PAD heat source are particularly significant when considering capsule material problems. Here even a few degrees reduction in operating temperatures can be critical.

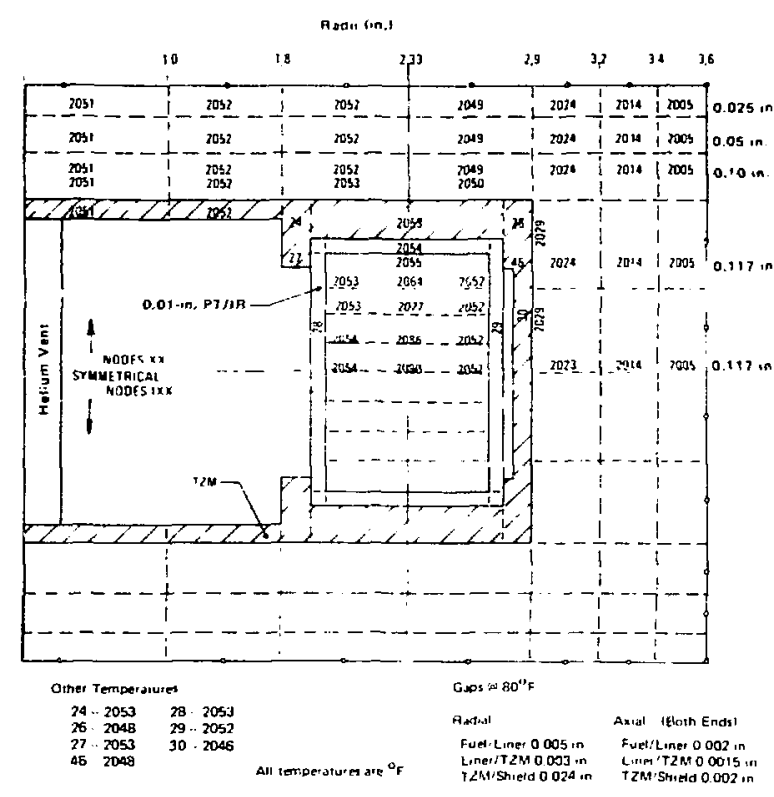

Fig. 2.

$P A D$ thermal model steady-state temperature.

As a further part of this effort, dimensional and ballistic characteristics were determined for about $\mathbf{5 0 0}$ different PAD heat source configurations using both plutonium and curium. Our initial intent was to determine whether an optimum heat source fuel inventory existed from a safety standpoint. No such optimum was found, but it appeass that there is a proportionality between various safery problems and heat source power density.

A basic PAD geometry without strength member was seiected to simplify the study. The fuel was in the form of 15-W cylinders of either plutonia or curia. Each fuel cylinder was encapsulated in a 0.02 -in.-thick noble metal container. The encapsulated fuel cylinders were embedded in a graphite $\left(1.65 \mathrm{~g} / \mathrm{cm}^{3}\right)$ heat shield.

A computer code was written to determine the characteristics of PADs containing various quantities of fuel from 45 to $300 \mathrm{~W}$ in steps of $15 \mathrm{~W}$. For each inventory. the heat shield diameter was varied in steps of 0.200 in. to permit examination of various ballistic coefficients for each fuel loading.

Computer code printouts are included in Appendix A. For each inventory, PAD dimensions and weights are listed together with ballistic coefficients, impact velocity, and power density.

After completing the plutonium study, we plotted the maximum values of these variables against the fuel inventory, as shown in Fig. 3. All variables peak at an inventory of 105-W, indicating that from a safety standpoint, a 


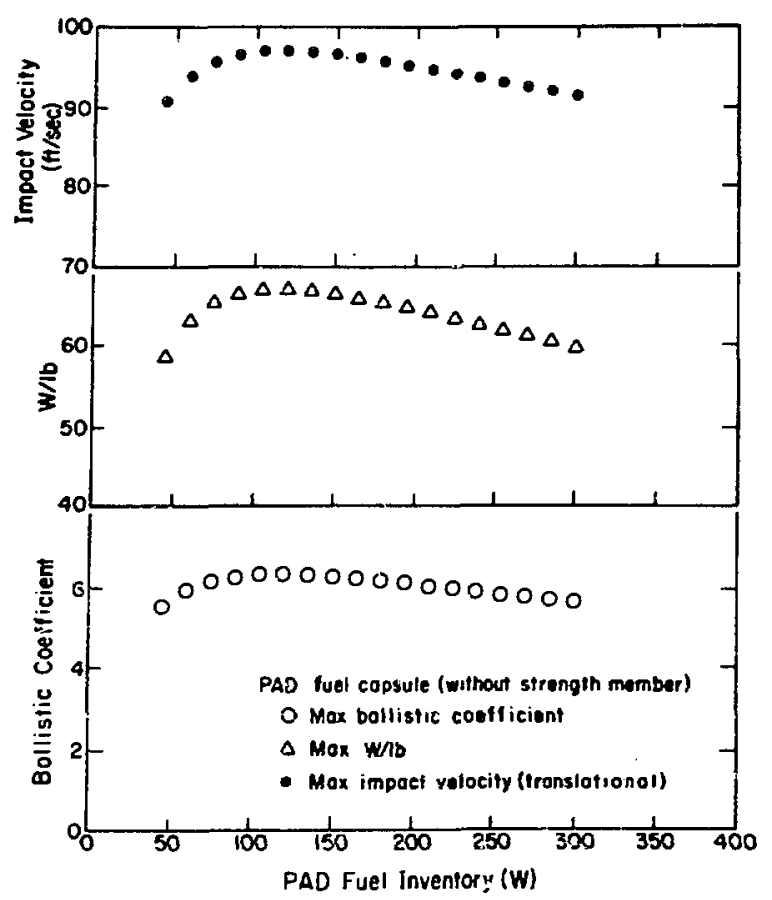

Fig 3.

$P A D$ fuel capsule characteristics vs fuel inventory.

105-W pure plutonium oxide (FPO) PAD is the least desirable. However, the high-power density of the 105-W PAD is the most desirable from a system analysis standpoint, as shown in Fig. 4. Here impacx velocity is plotted against heat source power density for all inventories from 45 to $300 \mathrm{~W}$. A similar plot would result if ballistic coefficient (or maximum reentry heat rate) was substituted for impact velocity. Thus it appears that heat source power density rather than total inventory is the significant parameter from the standpoint of impact velocity and maximum reentry heating rate.

Irituitively, it appears that a similar situation exists in regard to a numbar of other safety problems. For instance, if a fuel capsule's power density is increased by removing a portion of its reentry shield, then its probability of surviving a launch pad fire, or impact, (and possibly reentry) will be reduced. Also, if shape (i.e., spherical, cylindrical, or flat plate) is used as a parameter, the postimpact temperature will also be found to be proportional to power density.

\section{B. Reentry Analysis}

The detailed results of the reentry analysis are reported in Refs. 1 and 2, where a 240-W unit having a strength

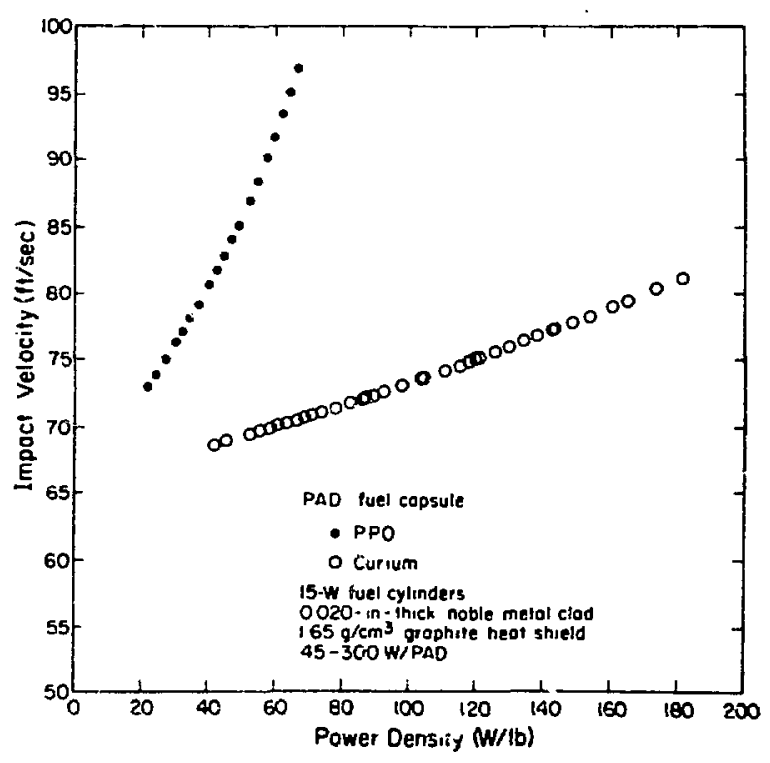

Fig. 4.

Impact velocity vs power density for PAD fuel capsule.

member and sized for the MHW generator was considered. During analyses the need for a strength member was uncertain. However, its inclusion made the analysis more conservative because it raises the PAD's ballistic coeffcient.

Because rentry experiments are prohibitively expensive, considerable effort was expended in manpower and computer time to generate and exercise mathematical models that would yield believable predictions of the modular disk heat source response to various reentry environments.

The trajectories were calculated in two ways. First, for most of the calculations, the modular disk heat source was as:umed to be a single reentry body independent of the spacecraft and generator at an initial altitude of $400,000 \mathrm{ft}$. Second, to investigate the effects of spacecraft breakup on heat source survivability, a near-vertical entry at $33,400 \mathrm{ft} / \mathrm{sec}$ was caiculated using the ballistic coefficient of an intact generator as the initiai condicion. In this caiculation, the ballistic coefficient was instantly changed to that of the modular disk heat source at various assumed brikatup altitudes. This sudden exposure resulted in an increase in deceleration and a sudden onset of aerodynamic heating. This calculation showed little sensitivity of response to breakup altitude, but it did yield the maximum thermal stress condition.

The ablation of the graphite hear shield was investigated sor many trajectories, including single and muitipass 
entries. The calculations used the ablation equations of Metzger et al. ${ }^{3}$ in the reaction limited regime, of Scala and Gilbert ${ }^{4}$ in the diffusion limited regime, and of Scala and Gilbert $^{5}$ in the sublimation regime. The ablation was found to be significant only in two cases. For the entry at $-88^{\circ}$ and $33,400 \mathrm{ft} / \mathrm{sec}$, the ablation during the subsonic and hypersonic portions of tie flight was 0.033 and 0.010 in., respectively, for a total of 0.043 in. The range of entry angles that results in multiple passes through the earth's atmosphere was investigated. We found that only 0.100 in. of graphite would be ablated from the original 0.175 in. of material for the worst inultipass entry condition. The maximum component temperature trajectory ( $\mathrm{V}=35,700 \mathrm{ft} / \mathrm{sec}, \gamma=-25^{\circ}$ ) yielded peak component vemperatures that were below their melting points. This included the Pr/Ir fuel clad. Additional reentry insulation reduces these temperatures considerably without paying steady-state penalties. Calculations for steep angle reentries $\left(V=33,400 \mathrm{ft} / \mathrm{sec}, \gamma=-88^{\circ}\right)$ and low-altitude generator breakup, where thermal stress is most severe, showed that peak stress was $39 \%$ of the ultimate strength for a POCO heat shield. For a MOD 3 heat shield, peak stress was $23 \%$ of ultimate strength. Impact testing shows that carbon composites are superior to molded graphites for impact protection. However, the low PAD terninal velocities du not require graphite for impact protection. Thus, either type of graphite is acceptable provided excessive fuel capsule power density with resulting high-impact velocities is not required to adequately integrate the PAD with the generator.

We concluded from the reentry studies that the PAD concept is generally confirmed. Choice of heat shield material is not critical. If the application is such as to allow the steady-state heat flow to be radial and thus normal to the direction of reentry heat flow (which is the case for PAD heat sources in carrent RTGs), component temperatures on reentry can be reduced further while maintaining the advantage of low oparating temperature gradients.

\section{Launch Abort}

The only analysis in this area is reported in Ref. 1. Esititivi conciusions are that the PAD capsule would survive a Pioneer fireball and liquid residual fire with good margin and would probably survive a Pioneer solid propellant firs, but not a double proximity MHW solid propelIant fire.

The fire analysis presents numerous modeling difficulties associated with the boundary definition. Thus, we cannot make firm statements about the PAD's response to this environment, but it appears highly probable that the PAD would not survive the so-called double proximity fire without some additional protection. As mentioneo' above, one must rely on the low probability of breaching a large quantity of PAD fuel in the extreme environment of a double proximity fire. Also, the improvements that might be available from using additional "reentry" insulation have not been fully explored.

\section{Postimpact Analycis}

Here again a standard thermal analysis model does not exist. Reference 1 reports the results of a very conservative analysis on a $240-W$ PAD with a molybdenum strength member. The reported temperature was $400^{\circ} \mathrm{C}$. Removing the strength member will increase the remperature of the individual cladded fuel pellets, but not beyond the oxidation capabilities of the noble metal clad.

Postimpact temperatures are quite sensitive to variations in environments caused by surrounding objects, winds, and degree of capsule burial. The lack of a standard boundary makes it impossible to compare different fuel capsule designs based on absolute temperatures. However, a good guide is the total capsule invencory divided by the surface area of the capsule (surface heat flux). If all capsules were in the same environment, their temperatures would differ almost exactly as the surfase incat flux differed. The figures for a number of capsules are given in Table I.

Based on the surface heat flux comparison, the PAD 15-W sphere would have a surface temperature about half that of the MHW sphere. Experimental observations oi MHW spheres show a surface temperazure of $\sim 600^{\circ} \mathrm{C}$, depending on conditions. Thus an approximate surface temperature of 200 to $300^{\circ} \mathrm{C}$ is projected for a $15-\mathrm{W}$ spherical pellet.

\section{TABLE 1}

SURFACE FLUX OF FUEL CAPSULES

\begin{tabular}{lcll}
$\begin{array}{c}\text { Fuel } \\
\text { Capsule }\end{array}$ & $\begin{array}{c}\text { Surface Flux } \\
\left(\text { W/in. }{ }^{2}\right)\end{array}$ & \multicolumn{1}{c}{ Comments } \\
\cline { 1 - 1 } Pioneer & & & \\
Transit & 17.8 & & Heat shield removed \\
MHW & 20.2 & & Heat shield removed \\
PAD (Ref. 1) & 14.8 & & No graphite \\
PAD 15-W cylinder & 3.9 & & Heat shicld removed \\
PAD 15-W sphere & 5.8 & & No graphite \\
& 7.6 & & No graphite
\end{tabular}




\section{EXPERIMENTAL PAD EFFORT}

\section{A. Air Drop Tests}

Ten models of a PAD heat source module were released from an aircraft and observed by radar. The initial launch attitude, spin rate, and mass of the models were varied. Significant mode of flight and terminal velocity differences were observed among models of different mass and different launch attitudes. Surprisingly, the models launched edge down and spinning had a lower terminal velocity than models of the same size and mass launched at other attitudes. The mean drag coefficient and lift-todrag ratio were fourd to be $\mathbf{1 . 1 8}$ and 0.285 , respectively. The total sea-level velocity of the models was found to be well correlated as a function of mass per unit frontal area. The demonstrated terminal velocity of the modular disk heat source, about $88 \mathrm{ft} / \mathrm{sec}$ for the Ref. 1 design, is only about $33 \%$ of that of existing heat source designs. Other test details can be found in Ref. 6 .

\section{B. Hypersonic Wind Tunnel Testing}

Before the aerodynamic advantages of the disk module design can be realized, two events must occur after tine disk pack is separated from it: -ontainer: the disks must separate from one another, and each must assurne a stable, flat-face-forward attitude. To determine whether both events will occur, the separation conditions were simulated in the Ames Hypervelocity Free-Flight Aerodynamic facility. In this facility, models are fired from a light gas gun into a long chamber held at a controlled pressurc. A careful study of sequential photographs taken at different stations in the long chamber revealed that the disks quickly separate and fly as if they had been released as single bodies. These same photographs also show that the disks soon seek a stable, flat-faced-forward attitude in hypersonic flight.

\section{C. impact Testing}

Developmental impact testing is now in progress with 15-W $\mathrm{UO}_{2}$ fuel simulant pellets $\mathbf{9 0 - 9 5 \%}$ theoretical density). Both the cylinders and the spheres are being tested with and without graphite protection. All pellets have had 0.020 -in. Pt/It containers. Drawings of the test components are included in Alpendix $B$.

Testing has been done with both an air gun and explosively driven steel plates. The air gun permits good highspeed camera coverage of the impact. Gases from the explosion tend to blur camera coverage. However, the explosive technique has no significant size limitation, permits "soft" recovery, and offers the potential for instrumenting the stationary modeis.

Because of the high cost of using the MOD-3 graphite, Carbitex was substituted. The impact models contain only one cladded fuel pellet. When graphite was used, its dimensions were 0.6 in. thick radially and 0.14 in. thick axially. Tests with mulsiple fuel pellets will be conducted later. The testing was done at room temperature, which is on the conservative side of the expected impact temperature. Initial tests used a stcel target with "as-rolled" hardness. Later, a hardened steel taryer vas used.

For each cylinder test in the air gain, it was intended that the model impact "edge-on." "inwever, the models usually tumed slightly beiore impact so that the model's center of gravity and comer were approxinsarely aligned with the velocity vector at impact. Most of these "corner" impacts were directly on the weld, but in no case did the weld break.

Table II is a summary of the teste run to date. Survival in the table is definest as impact without any breach of the clad.

The impacts were recorded on high-speed film. To establish the timing for the film, preiiminary shots were fired using an inexpensive molded graphite. These preliminary tests indicated that the graphite absorived negligiblc energy during the impact. However, the tests using Carbitex gave the opposite indication. To illustrate this, the clad in the sixth test had much less permanent deformation than the clad in the first test. The energy of the model in the first test was about one-fifth of the model energy in the sixth test.

The cylindrical clad failures in tests 4 and 5 appeared to be the result of excessive strain in the axial direction. The clad geometry had little internal resistance to axial deformation of the clad wall as compared with circumferential deformation. This indicates that a cylinder with a larger length-to-diameter ratio or even a sphere would probably have higher impact resistance. Tests 11 thrcugh 14 confirmed this indication.

All spherical models thus far have had defective welds. Test models 11 and 12 had large openings in the weld before testing. However, if it is assumed that a satisfactory weld can be developed, these test results can be useful. For instance, the breach in the weld of test 14 was only a hairline crack in the weld. However, there was sufficient clad deformation to indicate that even if the weld were sound, the clad was near the threshold of failure in other areas. The clad in test 13 had no perceptible permanent deformation after impact, indicating that a sphere with composite graphite protection probably has a much higher velocity capability. 
TABLE II

PAD IMPACT TESTS (15-W PELLETS)

\begin{tabular}{|c|c|c|c|c|c|c|}
\hline Test No. & $\begin{array}{l}\text { Velocity } \\
\text { (ft/sec) }\end{array}$ & Shape & Target & Graphite & Test Equipment & Survival? \\
\hline 1 & 78 & Cylinder & Cold rolled steel & None & Air gun & Yes \\
\hline 2 & 108 & Cylinder & Cold rolled steel & None & Air gun & Yes \\
\hline 3 & 155 & Cylinder & Cold rolled steel & None & $\mathrm{Ai}=$ gun & Yes \\
\hline 4 & 219 & Cylinder & Hardened steel & None & Air gun & No \\
\hline 5 & 172 & Cylinder & Hardened steel & None & Air gun & No \\
\hline 6 & 172 & Cylinder & Hardened steel & Carbitex $1^{a}$ & Air gun & Yes \\
\hline 7 & 230 & Cylinder & Hardened steel & Carbitex $1^{2}$ & Air gun & No \\
\hline 8 & 230 & Cylinder & Hardened steel & Carbitex $1^{a}$ & Air gun & Yes \\
\hline 9 & 155 & Cylinder & Hardened steel & None & Air gun & No \\
\hline 10 & 230 & Cylinder & Hardened steel & Carbitex $2^{\mathrm{b}}$ & Air gun & Yes \\
\hline 11 & 205 & Sphere & Hardened steel & None & Explosive & $\mathrm{No}^{\mathrm{c}}$ \\
\hline 12 & 155 & Sphere & Hardened steel & None & Explosive & $\mathrm{No}^{\mathrm{c}}$ \\
\hline 13 & 205 & Sphere & Hardened steel & Carbitex $2^{b}$ & Explosive & Yes \\
\hline 14 & 220 & Sphere & Hardened steel & None & Air gun & $\mathrm{No}^{\mathrm{c}}$ \\
\hline
\end{tabular}

\footnotetext{
${ }^{a}$ Laminations parallel to velocity vector.

${ }^{b}$ Laminations perpendicular to velocity vector.

${ }^{c}$ Models had defective clad welds. Clad breaches, if any, occurred in weld area well away from the impact zone.
}

Based on these tests, it appears that the 15-W PAD fuel pellet will have a very high probability of impact survival without a strength member at the expected impact velocities $(\leqslant 100 \mathrm{ft} / \mathrm{sec}$ ). Additional planned effort in this area is described in Sec. $V$.

\section{Vent Development}

Development work has started on a new vent concept that combines clad screen and powder. LASL has fabricated numerous "frit" type vents for plutonium glovebox lines and shipping containers. Some of these vents were made with layers of screen and others by standard powder inetallurgy techniques. In the first case, layers of screen are pressed together at high temperatures to produce diffusion bond joints between adjacent layers of screen. The vents were made with steel, copper, and noble metals. The screen vents have higher mechanical strengths, whereas the powder vents result in smaller particle retention. A plain screen vent for fuel capsule applications would require a screen with extremely small openings and would be prohibitively expensive, if obtainable.
For the PAD app!:cation, a screen with a more-or-less standard $(\sim 100)$ mesh and spheroidized powder will be tested. The diameters of the powder particles will be about the size of the openings in the screen $(\sim 0.003 \mathrm{in.})$. A particle of powder will be positioned in each screen opening of each layer of screen before the pressure/ temperature bonding of the layers. The finished vents will then be diffusion bonded into openings in the fuel clads.

The fabrication feasibilicy of the combined screen and powder vent has been demonstrated. Actual vents were fabricated using copper, which included both the screen to powder bonds and the vent to clad bonds. Commercial sources for noble metal screen and spheroidized powder have been found. Also, a helium test loop was constructed around a Granville-Phillips automatic pressure controller. This loop will determine the flow rate-pressure drup characteristics of test vents. The test vents wiil be made from copper until the proper combination of screen and powder sizes has been determined.

The flow specification for these vents has been set assuming a 15-W PPO fuel helium release at between $6 \times 1 \sigma^{-7}$ and $6 \times 1 \sigma^{-4}$ standard $\mathrm{cm}^{3} / \mathrm{sec}$, with a minimum pressure d'..p of $0.1 \mathrm{~atm}$. 


\section{E. Clad Compatibility}

Because thermodynamic data pertaining to intermetallic compounds of plutonium and precious metals are not available, we cannot predict whether or not a system consisting of graphite, platinum-25 iridium, and plutonia is. compatible at the projected operating temperatures.

Experimental testing of the system graphite-iridiumplutonia in support of the MHW program indicates that iridium metal is an acceptable container material for plutonia at $1450^{\circ} \mathrm{C}$. However, reaction of platinum and platinum-rhodium alloys with plutonia has been observed in reducing atmospheres at $1000^{\circ} \mathrm{C}$ (see Ref. 7).

We examined two test assemblies consisting of an unvented, two-compartment capsule of platinum-25 iridium containing a pellet of stoichiometric plutonia and a pellet of graphite separated by a partition with a 0.003 -in.-diam. hole, heated at $1150^{\circ} \mathrm{C}$. No reaction between the test components was observed after $985 \mathrm{~h}$. These results should not be considered conclusive because the capsule was not vented to vacuum and reactions may have been limited by attainment of equilibrium gas-phase compositions in the very small free volume in the assembly. Additional testing is required as described in Sec. V.

\section{F. Fuel Pellet Production}

Eight fabrications of cylindrical plu tonium PAD pellets were completed. Each fabrication involved a simultaneous pressing of eight pellets. Although all pellet dimensions are $\sim 0.90$-in. diam by 0.34 in. thick, varying die designs were used to form some of the specimens with the desired chamfers.

These developmental fabrications explored differences in pre- and postpressing thermal equilibrations by microstructural and chemical characterization of the product. Dimensional variations among the simultaneously fabricated pellets were acceptably low, averaging \pm 0.004 in. Typical immersion densities of $85-90 \%$ were attained.

Some cracking was observed in these prototype pellets, particularly in those with asymmetric chamfers. Further studies are in progress to eliminate this effect. It may be necessary to vary the tength-to-diameter ratio to ensure higher production yields.

One simultaneous pressing of four $15-\mathrm{W}$ spherical pellets was also completed. Although some of the pellets had surface cracks after heat treatment at $1600^{\circ} \mathrm{C}$, initial indications are that these pellets have satisfactory properties.

\section{G. Platinum-Iridium Fabrications}

In support of the impact testing, experierice was gained in the fabrication and welding of both $\mathrm{Pt} / \mathrm{lr}$ cylindrical and spherical clads (0.02 in. thick). Drawings for these parts are included in Appendix $B$.

The cylindrical configuration consists of a cup and a flat lid, whereas the spherical configuration consists of two hemishells. All parts were formed from fully annealed sheet material. Some thirning ( 0.002 to 0.003 in.) was noted in both the walls of the cups and near the poles of the hemishells. The weld joints were machined after forming. The material appears to machine similar to tool steel.

About 20 cylindrical assemblies were TIG welded. After a few test welds, the proper set of weld parameters was found, resulting in full weld penetration without danage to the $\mathrm{UO}_{2}$ simulant fuel pellets. The drawings in Appendix $B$ show a 0.032 by $45^{\circ}$ chamfer at both ends of the $\mathrm{UO}_{2}$ fuel cylinders. The chamfer had to be increased to 0.06 by $45^{\circ}$ adjacent to the weld to assure that the $\mathrm{UO}_{2}$ pellet did not crack during welding. This weld was quite successful in that it has never failed during it 0 impact tests, although mosĩ of the tests impacted directly on the weld.

The weld development of the spherical system is incomplete. A completely satisfactory weld has yet to be made after five attempts. The difficulties were attributed to the difference in material thicknesses between the male and female hemishells. New male shells are being fabricated with simple step joints in an effort to eliminate the welding problems.

\section{ADDITIONAL PAD EFFORT}

The following outlines additional PAD effort required to complete the generalized PAD development. The completion of the following, together with work done to date, thispld yield a sufficient. data base so that we can proceed with the design and development of a PAD fuel capsule for a specific generator. Items such as the generator operating temperature and the required fuel capsule power density will greatly influence any specific fuel capsule design. Until such items are specified, only a limited amount of additional effort will be profitable.

\section{A. Capstile Materials}

More fuel compatibility testing is needed. Present data suggest that noble metals or their alloys will probably be 
compatible if appropriate temperatures are used. However, temperature ranges of usefulness need to be defined for each potential alloy, unexpected reactions sought, and long-term tests done to verify the chemical and metallurgical stability of proposed configurations.

Experiments currently in progress or being planned that will contribute additional information include:

(1) An assembly consisting of a vented, full-sized Pt-25 Ir PAD fuel module contained in a graphite capsule is being exposed in vacuum at $1150^{\circ} \mathrm{C}$.

(2) A limited number of small capsule, compatibility tests are being assembled to compare the compatibility characteristics of plutonia with commercially pure platinu $n$, platinum-25 iridium, and platinum-30 rhodium-8 tungsten. This series of tests is designed to be conducted in a sealed capsule of molybdenum with a zirconium getter io provide an atmosphere of low oxygen partial pressure. Initially, an assembly of each alloy will be heated at $1000^{\circ} \mathrm{C}$ for about 1 month. Pending these exposure results, a duplicate assembly will either be given a longer term exposire at the same temperature or another temperature will be selected.

\section{B. Weld Development}

Additional effort will be required to develop a satisfactory weld joint and, hopefully, to prevent cracking of the fuel during the welding of a spherical clad. This will require the fabrication of additional noble metal clads for test welds and, possibly, the evaluation of an internal weld shield. The success with the cylindrical weld also suggests the possibility of fabricating and encapsulating hemispheres, or fabricating the fuel sphere with a cylindrical section adjacent to the weld so that there will be additional clearance in this area. These approaches to preventing fuel cracking may also be investigated. Weld parameters for other candidate clad materials such as $\mathrm{Pt} / \mathrm{Rh}$ should also be determined. Completion of this effort is a prerequisite to completing the impact testing effort.

\section{Vent Development}

Vents are being fabricated from copper to determine the mesh and powder sizes required to obtain the proper flow characteristics. Ultimately, these vents will have to be made from $\mathrm{Pt} / \mathrm{Ir}$ or other candidate materials. After the flow characteristics have been determined, these vents will be heated above typical operating temperature for extended periods to check for changes in flow characteristics. Also, tests should be conducted to determine the particle retention capability of the vents. Finally, impact tests of vented clads will be required to assure that the vents do not cause clad breaches at expected impact velocities.

\section{Impact Testing}

Based on present tests, spherical geometry is probably far superior to cylindrical geometry at impact. However, this conclusion cannot be definite until spherical weld development has been completed, at which time additional impact tests will be conducted.

In addition, impact tests with actual PPO fuel and multiple fuel pellet models are required. PPO fuel will require some changes in testing techniques. Multiple fuel pellet models will determine whether there is any adverse interaction between the pellets at impart.

Impact tests of vented clads and clads with alternate materials will also be required. Also required will be some data on the effect of impact on the clad emissive coating.

\section{E. Fire Test}

Analytical work on the solid propellant fire is uncertain. Any safety review will rely heavily on empirical data in this area. This is especially true for a PAD capsule, because any credible worst case will have a significant probability of fuel release. Thus, it is desirable to conduct solid propellant fire tests on PAD models.

These rests will determine the capability of PAD components in the fire environment, that is, how long they can survive or how large a piece of fuel is required to cause a breach in the clad. These data, together with data on solid propellant breakup (such as in Ref. 8), should be sufficient to compute source terms for this ersvironment.

\section{F. Fuel Pellet Development}

As with any new fuel configuration, some trial fabrications will be required. These fabrications will be aimed at selecting the proper fabrication parameters (i.e., feed material, die design, etc.) to assure the highest possible production yield and dimensional stability for the PAD pellets. The limited dimensions of the PAD pellets should result in a relatively short development cycle in this area. 


\section{REFERENCES}

1. J. J. Burns, J. W. Vorreiter, w. C. Pitts, and T. W. Conway, "Plutonium Aerodynamic Disc (PAD) Safety Fessibility Study," AEC-Space Niclear Systems Division report SNS-975 (November 1972).

2. J. W. Vorreiter, J. J. Burns, W. C. Pitts, and H. A. Stine, "Atmosphere-Entry Behavior of a Modular, Disk-Shaped Isotope Heat Source," Eighth Intersociety Energy Conversion Engineering Conference, Philadelphia, PA, August 13-17, 1973.

3. J. W. Metzger, M. J. Engel, and N. S. Diaconis, "The Oxidation and Sublimation of Graphite in Simulated Re-Entry Environments," AlAA Thermophysics Specialists Conference, Montercy, CA, September 13, 1965, Faper 65-643.

4. S. M. Scala and L. M. Gilbert, "Acrothermochemica" Behavior of Graphite at Elevated Temperatures," Gcneral Electnc report R63SD89 (November 1965).
5. S. M. Scala and I. M. Gilbert, "Sublimation of Graphite at Hypersonic Speeds," AlAA Journal, 3, No. 9, 1635-1644 (1965).

6. J. W. Vorreiter and D. L. Tate, "Observations of Disk-Shaped Bodies in Free Flight at Terminal Velocity," NASA report TMX-62, 262 (March 1973).

7. J. E. Selle, J. R. McDougal, and D. R. Schefer, "The Compatibility of Plutonium-238 Dioxide with Plutinum and Flatinum-Rhodium Alloys Interim Report," Mound Laboratory report MLM 1684 (January 1970).

8. R. Coffey and T. W. Conway, "A Model of the Sulid Propellent Fragments From a Launch Abort of a Titan III $C$ Launch Vehicle," NUS Corporation report NUS-TM-S-148 (November 1972). 
PAD FUEL CAPSULE DESIGN SYNTHESIS

PAD FUEL CAPSULE (WITHOUT STPEHCJI HEMBER)

\section{HATTS2}

3.745

3.945

4.345

4.545

4.745

5.145

5.345

5.745

5.945

6.315

6.545

6.745

6.945

7.145

7.345

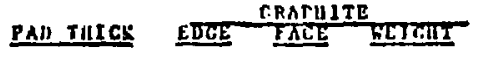

\section{.704}

.690

.685
.680

.075

.071

.065

.662
.659

.0075

.653

.651

.647
.646
.065

.0645
.154

.151
.147
.145

.142

.160

.138

.136

135
.133

0132

$: 131$

.129

.128

126

125
$: 125$
$: 124$

.125
3 FUEL CrL 15 WATTS

$(.90010=.341 \mathrm{ls})$
HIN TAD DIA $=3.745$

HIN GRAPLITE DIMLNS EDRE TR - . $350^{\circ}$

FUEZ WE IEIT : 24408

FUEl Cri CLEA - . .125"

LUPACT VELOCSTX UATT(TI)/FOLAD

90.7
88.6

88.6

85.1

:2.3

81.2

79.2

78.3

77.6

76.9

75.6

75.1

74.6

74.1

$72: 9$

58.621

55.351

49.429

46.755

44.256

41.923

39.743

35.804

$32: 025$

30.874

29.346

27.28 ก

26.699

24.368

$23: 307$
PAD FUEL CAPSULE (HITHOUT STREAGTH MEMBER)

\section{WATTS:}

\begin{tabular}{|c|c|c|c|c|}
\hline & & \multicolumn{3}{|c|}{ GRAFHITE } \\
\hline PAD DLA & PAD TUICE & EDAR & TKCE & METHit \\
\hline $\begin{array}{l}4.030 \\
4.230 \\
4: 430 \\
4.630 \\
4: 830 \\
5.030 \\
5.230 \\
5.430 \\
5.630 \\
5.830 \\
0.030 \\
6.230 \\
6.430 \\
6.630 \\
6.830 \\
7.030 \\
7.230 \\
7.430 \\
7.630 \\
7.830 \\
8.030 \\
8.230 \\
8.430 \\
8.630 \\
8.830\end{array}$ & 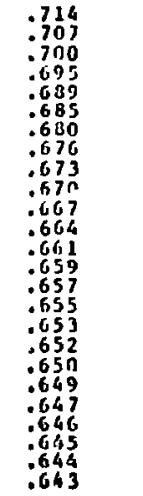 & 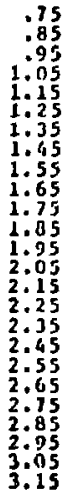 & 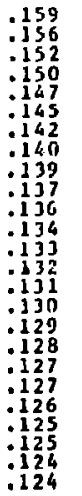 & $\begin{array}{l}.471 \\
: 520 \\
.571 \\
: 628 \\
: 680 \\
: 738 \\
.793 \\
.860 \\
.925 \\
.912 \\
1.061 \\
1.132 \\
1.206 \\
1.242 \\
1.360 \\
1.441 \\
1.524 \\
1.609 \\
1.696 \\
1.786 \\
1.878 \\
1.973 \\
2.069 \\
2.168 \\
2.269\end{array}$ \\
\hline
\end{tabular}

- PUEL CYL 15 HATTS

$(.90015 \times .34125)$

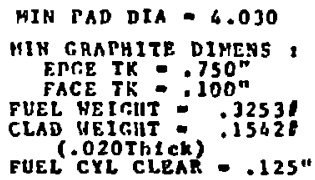

TOTH. TAD UEIGIT BAL COEF IMTACT VELOCITY HATT(Th)/POUMD

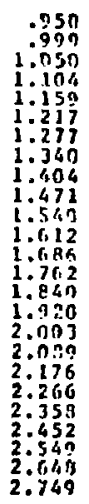

j,

3.85
3.80

3.76 
FAD TURL CARSOLE (UITLOTT STREHRTU HEHAER)

25 uarts:

3 TUEL CRL $1 S$ UATTS

(.9n DSE $2.341 \mathrm{Le})$
HEW PAD DLA - 4.266

Mz: cRApHite otmems , eder ix =

TOE YEIfor : 10.006

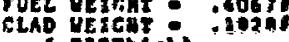

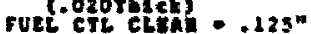

GRAPHITE

\begin{tabular}{|c|c|c|c|c|}
\hline & & \multicolumn{3}{|c|}{ GRAPHITE } \\
\hline P.AD DIA & PAD THLCX & EDTE & IXCI & YeTrin \\
\hline $\begin{array}{l}4.346 \\
4.546 \\
4.746 \\
4.246 \\
5.146 \\
5.346 \\
5.346 \\
5.746 \\
5.946 \\
6.146 \\
6.346 \\
6.546 \\
6.746 \\
6.946 \\
7.146 \\
7.346 \\
7.546 \\
7.746 \\
8.966 \\
.146 \\
0.346 \\
8.746 \\
0.946 \\
.146\end{array}$ & $\begin{array}{l}.620 \\
.713 \\
.706 \\
.701 \\
.675 \\
.690 \\
.686 \\
.682 \\
.678 \\
.675 \\
.672 \\
.669 \\
.667 \\
.664 \\
.662 \\
.650 \\
.658 \\
.656 \\
.654 \\
.653 \\
.652 \\
.650 \\
.649 \\
.668 \\
.666\end{array}$ & $\begin{array}{l}.75 \\
.65 \\
.05 \\
1.05 \\
1.15 \\
1.25 \\
1.35 \\
1.45 \\
1.55 \\
1.65 \\
1.75 \\
1.05 \\
1.95 \\
2.05 \\
2.15 \\
2.25 \\
2.35 \\
2.45 \\
2.55 \\
2.65 \\
2.75 \\
2.95 \\
2.95 \\
3.05 \\
3.15\end{array}$ & 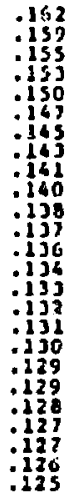 & $\begin{array}{r}.566 \\
.390 \\
.659 \\
.712 \\
.771 \\
.133 \\
.897 \\
1.993 \\
1.031 \\
1.102 \\
1.275 \\
1.230 \\
1.328 \\
1.407 \\
1.490 \\
2.374 \\
1.661 \\
1.769 \\
1.842 \\
1.936 \\
2.030 \\
2.128 \\
2.228 \\
2.331 \\
2.436\end{array}$ \\
\hline
\end{tabular}

\author{
Eet. noter
}

6.18

3.9.

3.67

3.in

6.72

4.54

6.39

$\because: 3$

:in

:.nष

$3: 98$

3.84

3.76

$3: 63$

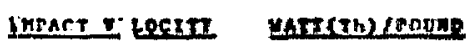

t): 7

45.70

33.0

34.17

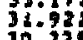

3.610

2.536

2.728

3.:036

a:3

if:3i

27 :

59.46

31:35

37.25

$34: 706$

30.51

42. 35

30.308

$37: 33$

童:

PAD FUEL CAPSULE (WITHOUT STERATI MEroEa)

90 Uatrs:

PAD DIA

SAD rHICx

$4.675 \quad 0723$

$5.075 \quad .710$

5.675

5.673

3.675

6.075

6.235

6.675

6.635

7.075

7.475

7.675

3.875

8.075

8.475

8.675

9.075

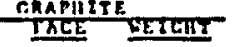

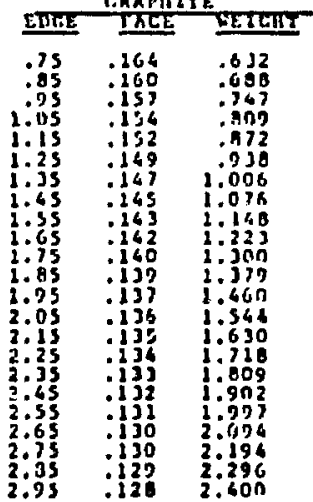

- ruel crl is uarss

$(.9001 .=.34226)$
IOTAL SAD UEIOHT

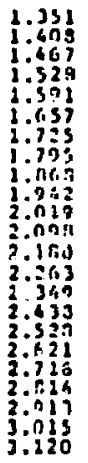

1AL COEF

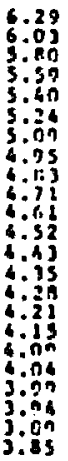

MIK BAD DLA - . .6T3

Hix caApuTE DEHEHS EOrE TK: $750^{m}$

FutL verent:

(.0207ther

puef crl cLith . .125"

IMPACS PELOCETY HatT(Th)/ROUND

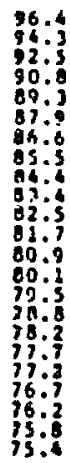

66.596

$61: 902$

50.173

36.532

34.293

32.157

Ai:iz

48.326

44.562

42.1381

4.280

30.759

36.912

35.591

33.12

31.282

30.85

29.863 
7 rab́ ETL 19 uATts

(.20 Dia $=.342$ 25)
14. PAD DIA W

giq ekarllte otueH: EDCE IK $=$. 730 " FACE IF : 100"

Tlet Yritht:-.3698

r.ozorhlek

rust cti ctiak - .12:"

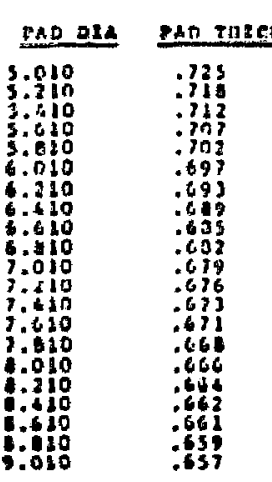

\begin{tabular}{|c|c|c|}
\hline \multicolumn{3}{|c|}{ contuIII } \\
\hline 23 & +2 & $1+21$ \\
\hline 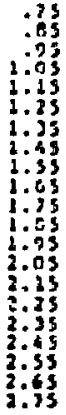 & 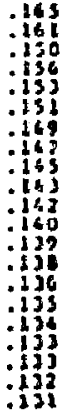 & $\begin{array}{l}.725 \\
.789 \\
.649 \\
.914 \\
.952 \\
1.031 \\
1.173 \\
1.197 \\
1.276 \\
1.352 \\
1.433 \\
1.316 \\
1.602 \\
1.690 \\
1.780 \\
1.922 \\
1.964 \\
2.065 \\
2.162 \\
2.264 \\
2.367\end{array}$ \\
\hline
\end{tabular}

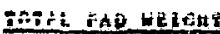

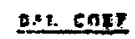

11PACT YELOCETI

HATE(Tt) /raLaD

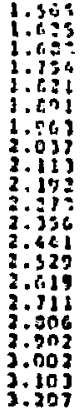

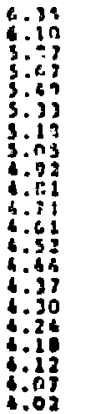

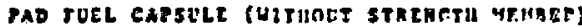

120 varsed

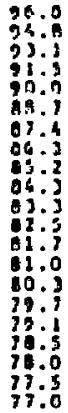

6). 0 9 0

0.281

C. 2.172

37.646

$\$ 3.320$

33.417

31.540

47.805

4 ing

46.360

4.511

4. 005

30.13

36.190

34.94

$33,7 \in 0$

FiL as WATt

HTH TAD DIA - 3.34?

MER CAAPIIIE OIHEHS, Coce TR - .750"

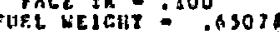

FUFL WEICHT - ASOJ

Futétert CLER - . $24 \mathrm{~g}$

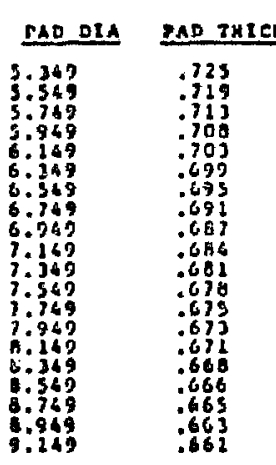

\begin{tabular}{|c|c|c|}
\hline EDTA & $\frac{\text { GeApli }}{\text { rate }}$ & $E_{\text {te. }}$ \\
\hline 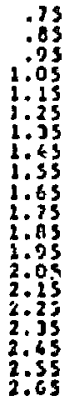 & 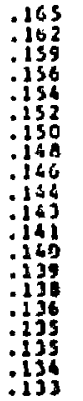 & $\begin{array}{r}.027 \\
.092 \\
.259 \\
1.028 \\
1.099 \\
1.173 \\
2.249 \\
2.327 \\
1.408 \\
1.497 \\
1.575 \\
2.662 \\
1.732 \\
1.844 \\
1.938 \\
2.094 \\
2.132 \\
2.233 \\
2.316 \\
2.462\end{array}$ \\
\hline
\end{tabular}

TOTAL PAN HELCAI

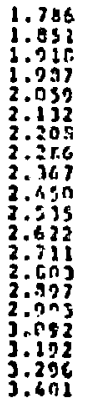

set cozz

6.35

5.

$3.3_{3}$

$3: 26$

3.12

i.t.

4.71

4.80

4.31

4.37

$4: 3 n$

$\$: 13$

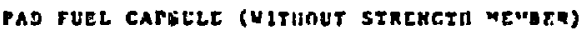

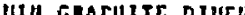
EnAE TK $-75 \pi^{\circ}$

FURL HEICIIT - .73204

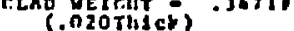

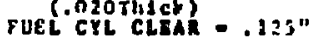

SAD oLd enp tilex

LITE CRATILTE

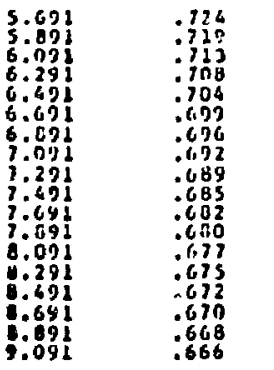

\begin{tabular}{|c|c|c|}
\hline $\begin{array}{l}.15 \\
.85 \\
.25 \\
1.05 \\
1.15 \\
1.25 \\
1.35 \\
1.45 \\
1.55 \\
1.65 \\
1.75 \\
1.65 \\
1.25 \\
2.05 \\
2.15 \\
2.25 \\
2.35 \\
2.45\end{array}$ & 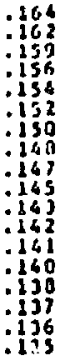 & 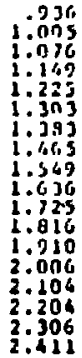 \\
\hline
\end{tabular}

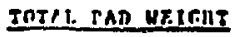

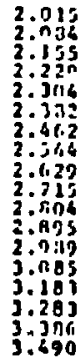

OAL COEF

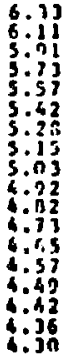

IKrACt Pcloctet

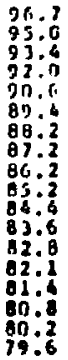
64.817 6..37? 38.276 36.262 $3: 47 \pi$ 30.685 47.318 65.763 64.253 41.417 4.038 37.381 36.607 35.279 


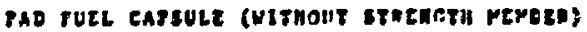

\section{NATFSI}

10 rtat CrL 15 uagrs

$(.70 \mathrm{nit}: .162 \mathrm{2a})$
HES TAD DLA $=6.034$

riH chaphtse pintws, enrfer to : ison

ruct yegent: : 1340

rutet cte stek)

$-.225^{\circ}$

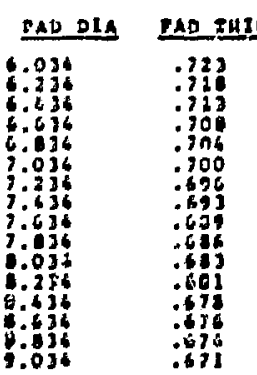

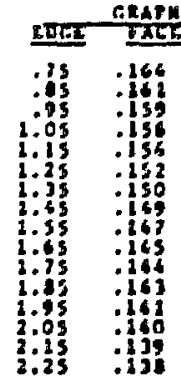

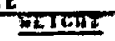

3.053

$\frac{1}{2: 126}$

1. 27,

1.440

2.326

1.810

1.079

i.tiz

1.970

2.015

2.175

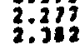

Intar. TaP UETeHT

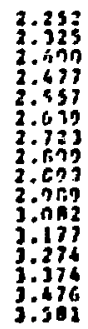

w. cant

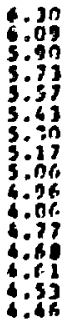

IMPACE VELOCITY yate(Th)/POUAR

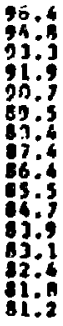

66.595

6.. 305

60.534

38.690

56.831

33.386

51.755

4.668

$47.20 \%$

4.802

4.163

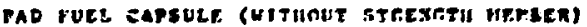

163 NATSS:

ingres

21 Fige r.t. 15 watrs

$$
(.50 \text { ot: } x .14228)
$$

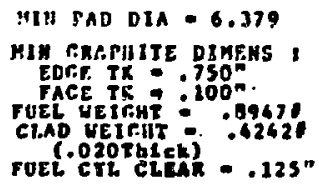

IirAct velocter uatr(Tii)/reupe

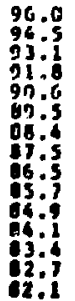

66.088

62.1

3.26
6.05

5.71

3.36

5.43

5.id

5.07?

4.38

8.71

6.63
4.56

PAD TUEL CASSULE (UITIOUT STAENATU MEHWEQ)

1 eo varTs:

$$
(.20010 \times .36220)
$$

\begin{tabular}{|c|c|c|c|c|c|}
\hline PAD DIA & PAD THICX & ETHE: & $\frac{\text { GRAFu }}{\text { Fakt: }}$ & zE & TOTAI. rAn HETrilt \\
\hline 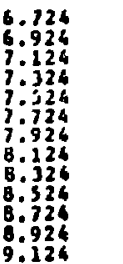 & 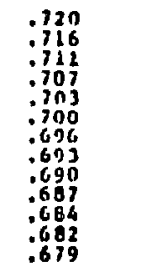 & $\begin{array}{l}.75 \\
.75 \\
.95 \\
105 \\
1915 \\
1125 \\
1.35 \\
11.65 \\
1.35 \\
1.65 \\
1.75 \\
1.85 \\
1.95\end{array}$ & $\begin{array}{l}142 \\
1160 \\
1130 \\
1136 \\
1134 \\
1152 \\
1190 \\
1149 \\
1167 \\
1146 \\
1144 \\
1143\end{array}$ & $\begin{array}{l}1.309 \\
1.390 \\
1.673 \\
1.537 \\
1.640 \\
1: 376 \\
1.629 \\
1.923 \\
2.620 \\
2.119 \\
2.220 \\
2.323 \\
2.429\end{array}$ & 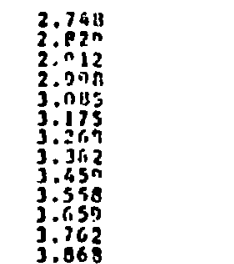 \\
\hline
\end{tabular}

GRAPU1TE

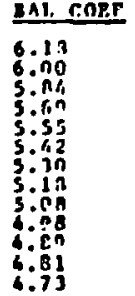

MTH PAO DIA - 6.724

HIS RIRARUITE DIMENS, EDRE TK : 7 750"

FULL WEIFilt: $\$ 97608$

(.020Tilek) .0628

fucl cri cleks = .125"

IHPACT Prino:ITY UATT(TI) /POUNP

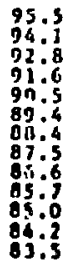

65.495

63.618

61.799

58.323

56.677

33.53

52.036

39:589

9.19

67.839 
195 NatTs:

PAD TUEL CAPSULE (WT TIOUT SFAEYGTU :AF'BER)

DAD DRA

\subsection{0}

7.270

7.070

8.070

8.470

9.870

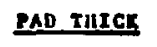

.719
7714
7710
7706
702
6999
6996
6693
6690
6685
.685

\begin{tabular}{|c|c|}
\hline$E \overline{D T E}$ & $\mathrm{IxC}$ \\
\hline $\begin{array}{r}.75 \\
.85 \\
.95 \\
.05 \\
.15 \\
.25 \\
.35 \\
.45 \\
.55 \\
.65\end{array}$ & $\begin{array}{l}162 \\
1159 \\
1159 \\
1155 \\
115 \\
153 \\
1152 \\
1150 \\
1149 \\
1147 \\
11 \$ 6 \\
1245\end{array}$ \\
\hline
\end{tabular}

WEITHIT

1.447
1.533
1.620
1.710
1.801
1.895
1.992
2.090
2.191
2.294
2.399

TOTAI. PAD HEIGAT

3.006
3.032
3.179
3.268
3.360
3.454
3.559
3.569
3.750
3.853
3.958

23 Puit, CYL 15 watrs

$(.90$ D1. $8.341 \mathrm{Ls})$

PAD FUEL CAPSULE (WTTHOHT STREKGTU HEHGER)

210 natrst

14 FUEL CYL $O$ IS watTS

$(.90$ Die $\times .341 \mathrm{Ls})$

PAD FUEL CAPSULE (HITHOIT STPENATH MRMBEP)

223 WATTS:

\begin{tabular}{|c|c|c|c|c|c|c|c|c|}
\hline IAD DIA & PAD THLCX & 1एत्ट & craph & TE & TOTAY, PAN VEICHT & BAL CAEF & IMTACT VELOCITT & HATT $(T h) / r n$ UHD \\
\hline $\begin{array}{l}7.421 \\
7.621 \\
7.821 \\
8.021 \\
8.221 \\
8.421 \\
8.621 \\
8.821 \\
9.021 \\
9.221 \\
9.421\end{array}$ & $\begin{array}{l}.717 \\
.713 \\
.709 \\
.705 \\
.702 \\
.694 \\
.695 \\
.692 \\
.689 \\
.687 \\
.684\end{array}$ & $\begin{array}{r}.75 \\
.85 \\
.95 \\
1.05 \\
1.15 \\
1.25 \\
1.35 \\
1.45 \\
1.55 \\
1.65 \\
1.75\end{array}$ & $\begin{array}{l}.161 \\
: 159 \\
: 157 \\
: 155 \\
: 153 \\
: 151 \\
1150 \\
1148 \\
1147 \\
1146\end{array}$ & $\begin{array}{l}1.596 \\
1.685 \\
1.776 \\
1.870 \\
1.964 \\
2.064 \\
2.164 \\
2.267 \\
2.372 \\
2.479 \\
2.588\end{array}$ & 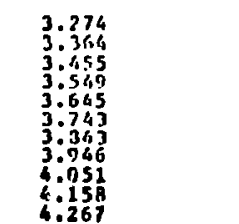 & $\begin{array}{l}6.05 \\
5.89 \\
5.75 \\
5.61 \\
5.47 \\
5.37 \\
5.26 \\
5.16 \\
5.07 \\
4.98 \\
4.89\end{array}$ & $\begin{array}{l}94.5 \\
93.3 \\
92: 1 \\
91: 0 \\
90.0 \\
89.0 \\
88: 1 \\
87.3 \\
86.5 \\
85.7 \\
85.0\end{array}$ & $\begin{array}{l}64.123 \\
62.422 \\
60: 770 \\
59: 167 \\
57: 610 \\
56.100 \\
54: 636 \\
53: 215 \\
51: 838 \\
50: 504 \\
49.2 !\end{array}$ \\
\hline
\end{tabular}

\begin{tabular}{|c|c|c|c|c|c|c|c|c|}
\hline IAD DIA & PAD THLCX & 1एत्ट & craph & TE & TOTAY, PAN VEICHT & BAL CAEF & IMTACT VELOCITT & HATT $(T h) / r n$ UHD \\
\hline $\begin{array}{l}7.421 \\
7.621 \\
7.821 \\
8.021 \\
8.221 \\
8.421 \\
8.621 \\
8.821 \\
9.021 \\
9.221 \\
9.421\end{array}$ & $\begin{array}{l}.717 \\
.713 \\
.709 \\
.705 \\
.702 \\
.694 \\
.695 \\
.692 \\
.689 \\
.687 \\
.684\end{array}$ & $\begin{array}{r}.75 \\
.85 \\
.95 \\
1.05 \\
1.15 \\
1.25 \\
1.35 \\
1.45 \\
1.55 \\
1.65 \\
1.75\end{array}$ & $\begin{array}{l}.161 \\
: 159 \\
: 157 \\
: 155 \\
: 153 \\
: 151 \\
1150 \\
1148 \\
1147 \\
1146\end{array}$ & $\begin{array}{l}1.596 \\
1.685 \\
1.776 \\
1.870 \\
1.964 \\
2.064 \\
2.164 \\
2.267 \\
2.372 \\
2.479 \\
2.588\end{array}$ & 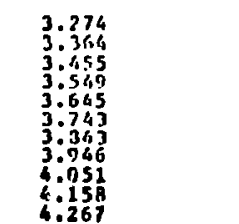 & $\begin{array}{l}6.05 \\
5.89 \\
5.75 \\
5.61 \\
5.47 \\
5.37 \\
5.26 \\
5.16 \\
5.07 \\
4.98 \\
4.89\end{array}$ & $\begin{array}{l}94.5 \\
93.3 \\
92: 1 \\
91: 0 \\
90.0 \\
89.0 \\
88: 1 \\
87.3 \\
86.5 \\
85.7 \\
85.0\end{array}$ & $\begin{array}{l}64.123 \\
62.422 \\
60: 770 \\
59: 167 \\
57: 610 \\
56.100 \\
54: 636 \\
53: 215 \\
51: 838 \\
50: 504 \\
49.2 !\end{array}$ \\
\hline
\end{tabular}

TOTAL. PAN UEICHT

\begin{tabular}{|c|c|c|c|c|c|c|c|c|}
\hline IAD DIA & PAD Tll & E:THCLC & 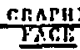 & TE & TOTAL, PAN UEICHT & BAL CNgF & IHTACT VELOCITI & VATt $(T h) /$ rnug \\
\hline $\begin{array}{l}7.421 \\
7.621 \\
7.821 \\
8.021 \\
8.221 \\
8.421 \\
6.021 \\
8.821 \\
9.021 \\
9.221 \\
9.421\end{array}$ & $\begin{array}{l}.717 \\
.713 \\
.709 \\
.705 \\
.702 \\
.695 \\
.895 \\
.692 \\
.689 \\
.687 \\
.684\end{array}$ & $\begin{array}{r}.75 \\
.85 \\
.95 \\
1.05 \\
1.15 \\
1.25 \\
1.35 \\
1.45 \\
1.55 \\
1.65 \\
1.75\end{array}$ & $\begin{array}{l}101 \\
.159 \\
1157 \\
1 \\
.155 \\
1153 \\
.151 \\
150 \\
1148 \\
1147 \\
1146 \\
1144\end{array}$ & $\begin{array}{r}1.596 \\
1.685 \\
1.776 \\
1.870 \\
1.966 \\
2.064 \\
2.164 \\
2.267 \\
2.372 \\
2.479 \\
2.588\end{array}$ & $\begin{array}{r}3.274 \\
3.344 \\
3.455 \\
3.549 \\
3.645 \\
3.743 \\
3.393 \\
3.946 \\
4.051 \\
6.156 \\
4.267\end{array}$ & $\begin{array}{l}6.05 \\
5.09 \\
5.75 \\
5.61 \\
5.40 \\
5.37 \\
5.26 \\
5.16 \\
5.07 \\
4.98 \\
4.89\end{array}$ & $\begin{array}{l}94.5 \\
93.3 \\
92.1 \\
91: 0 \\
90.0 \\
80.0 \\
88.1 \\
87: 3 \\
86.5 \\
85.7 \\
85.0\end{array}$ & $\begin{array}{l}64.123 \\
62.422 \\
60.770 \\
53.167 \\
57.610 \\
56.100 \\
54.636 \\
53.215 \\
51.838 \\
50.504 \\
\$ 9.2 !\end{array}$ \\
\hline
\end{tabular}

DAL COET

6.12
5.95
5.60
5.56
5.52
5.40
5.20
5.18
5.08
4.98
4.90
MIK PAD DIA - 7.070

MIK TRATHITE DIMENS, EDEE TK $=.750^{\circ}$

FUEL UE IGHT : 1.0574

CLAD WEIGHY .5014

FUEi CrL CLEA - . $125 "$

HPACT VELOCLIX NATI(Th)/TOUSD

$95: 0$
$93: 7$
$92: 5$
$91: 3$
$91: 3$
$89: 3$
$83: 3$
$87: 4$
$86: 6$
$85: 8$
$85: 0$

64.852

61.334

59.654

52.024

56.845

54.916

53.434

51.999

50.609
HIN PAD DIA -7.421

HIN GRATHITE DIMENS, EDFE TR: $750^{\circ}$

FUE

Fvê.

CI.X D.

FUEL CYL CLBAR - .125"

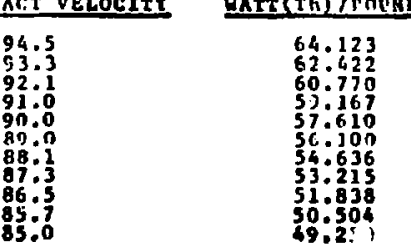

25 PUEL CYL 15 WATTS

$(.90015 \times .361 \mathrm{ke})$

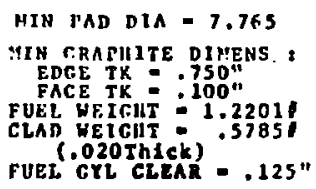

IHCACT VQLOCITT UATTSTH)/POLHD

$\begin{array}{ll}5.99 & 94.0 \\ 5.95 & 92.8 \\ 5.70 & 91.7 \\ 5.37 & 20.7 \\ 5.46 & 89.7 \\ 5.35 & 88.8 \\ 5: 24 & 87.9 \\ 5.14 & 87.1 \\ 5.05 & 86.4 \\ 4.97 & 85.6 \\ 4.89 & 84.9 \\ 4.81 & 84.3\end{array}$

63.125

61.801

60.222
50.687

57.197

55.749

54.344

51.655

50.370

49.124 


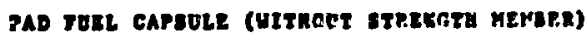

240 ustat

16 PUEL CYL 25 uATts

(.90 D14 $\times .342$ L8)
MIT RAD DIA - 8.115

M2: RiRAPHITE DIMENS , EOFE TE : 750 .

FUEL UEIGHT: 2.3014

(.02007h1ce)

PUEL CYL CEEA $=.125 \%$

PAO DE EAD THLEX

Din: ORAPUIR

TOTAL PAR MFIFIIT

8.113

$8: 513$

8.13

:.913

9.313

9.713

.713
7710
7706
7703
700
697
6994
691
689
686

.75
.85
.95
1.05
1.15
1.25
1.35
1.45
1.55
1.65

159
1137
155
1154
1152
1151
1169
1169
1148
1145

\section{$\frac{1}{2.0909}$}

2.106

2.312

2.418

2.637

2.750

2.865
DL engF

5.92

5.53

5.43

3.31

3.12

5.04
PAD TUEL CARSULR (WITHOUT STTEMCTh HR'BER)

27 Fucl crl if 19 watTs

$(.90014 * .341$ Le)

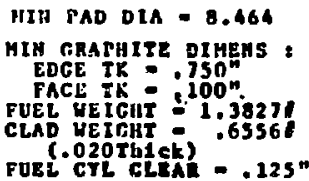

IMPACT VELOCLE HATE(Th)irouyo

92.9
$91: 9$
90.9
90.0
89.1
08.3
07.9

92.9

91.9

89.1

8.3

61.921

60.433

58.985

36.224

34.870

52. 323

62.688
61.134
53.623
58.153
56.724
55.335
53.985
52.674
51.400
50.163

$\begin{array}{cc}\text { PAD DIA } & \text { PAO THICK } \\ & .711 \\ 8.664 & : 708 \\ 8.864 & 7705 \\ 9.064 & .701 \\ 9.264 & .698 \\ 9.464 & .696 \\ 9.664 & .693 \\ 9.864 & .690\end{array}$

PAD FOEL CAPGULE (WTTHNET STKEATTH hEMBER)

18 FUEL CYL $P$ 15 watTS

$(.90 \mathrm{Dia} \times .341 \mathrm{Ls})$

TAD FUEL CAPSULE (HITHOUT STREHCTH MEMEER)

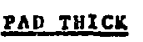

\begin{tabular}{ll} 
EDTE & GAPIII \\
\hline 75 & $: 157$ \\
$: 85$ & $: 155$ \\
$: 95$ & $: 154$ \\
$: 05$ & $: 152$ \\
$1: 15$ & $: 151$ \\
1.25 & $: 150$
\end{tabular}

HETmir

TOTAI. PAD HEZAIIT

2.253
2.359
2.466
2.576
2.6808
2.803

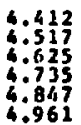

MAI. COEF

5.79

3.65

5.94

5.25

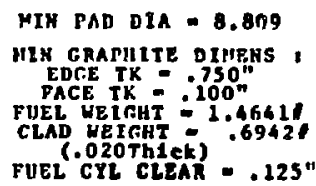

FuEl (.020Thiek)

. .125

\begin{tabular}{|c|c|}
\hline IMPACT VELOCITY & עaTt $(T h) / \Gamma 0$ \\
\hline $\begin{array}{l}92.4 \\
91: 4 \\
90.5 \\
89.6 \\
88.8 \\
80.0\end{array}$ & $\begin{array}{r}61.192 \\
59.764 \\
58.376 \\
57.020 \\
59.701 \\
54.428\end{array}$ \\
\hline
\end{tabular}

285 vatTS:
19 FUEL CTL 9 15 HATTS

$(.90 \mathrm{DLE} \times .361 \mathrm{Lg})$
MIN TAD DIA $=9.163$

IIN GRAPUITE DIUEHS ,

EDC.F TK : T50"

FUEL NEIGIIT: 1.5454

CLAD HEICUT: 1.7328

CLAo (.020Th(ek)

FUEL CYL CLIAR - .125"

\begin{tabular}{|c|c|c|c|c|c|}
\hline TAD DLA & PAN THICK & EDT:E & GRAFII & IE & TOTAL TAN HEIGIIT \\
\hline $\begin{array}{r}9.163 \\
9363 \\
9563 \\
9763 \\
9963\end{array}$ & $\begin{array}{l}708 \\
.705 \\
7702 \\
.699 \\
.696\end{array}$ & $\begin{array}{r}.75 \\
.85 \\
.95 \\
1.05 \\
1.25\end{array}$ & $\begin{array}{r}.156 \\
.155 \\
1153 \\
.152 \\
.150\end{array}$ & $\begin{array}{l}2.439 \\
2.548 \\
2.660 \\
2.774 \\
2.890\end{array}$ & $\begin{array}{l}4.717 \\
4.827 \\
4.938 \\
5.052 \\
5.169\end{array}$ \\
\hline
\end{tabular}

QAl. C.OEE

5.72
5.60
$5: 30$
5.39
5.30
IHTACT VELOCITI

UATT (Th) / TOIBR

91.9
90.9
90.1
89.2
80.4

60.610

59.039.

57.703 


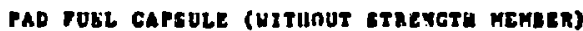

100 Hart:2

20 TOLL CVL 15 WATYः

$(.90010 \times .36125)$

PAD DIA PAD TULCE gTE GRAPHIEE

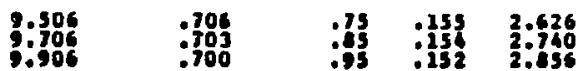

TOTAL PAD GEIGIIT

5.025
BAL COEP

5.66
5.55
MIH PAD DIA $=9.506$

MIH GRAPIIIE DIMEHS , EDSE TK

FUEA HETGIIT: 1.62680

CLAD HETGHT $=1.02680$

FUEL (.020ThLek) .

IBPACT YRLOCITY HATT(Th)/TOUAD

91.4

59.699
PAD PUEL CAPStLE (HITI CURSUM)

15 HATrs:

HIN PAD DIA -3.265

"II FAAFUITE DIHENS: EDCE TK $-.750^{\circ}$

FACE TK.: $100 \%$

FUCL NEIGHT : $\$ 07300$

(.020Thick)

FUFL CTL CLEAL - .125"

\begin{tabular}{|c|c|c|c|c|c|c|c|c|}
\hline PAD DIA & PAD IHICX & हTत्: & GRAPLI & EDEIfllt & TOTAL SAD UEIGUT & MAL COEF & IHFACT VELOCITY & $\operatorname{uart}(T h) /$ round \\
\hline 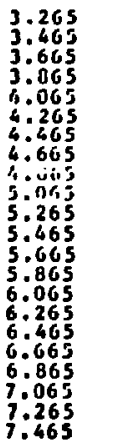 & 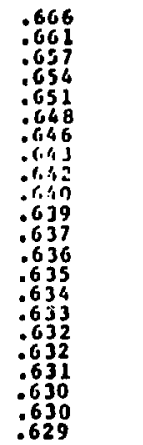 & $\begin{array}{l}.75 \\
: 05 \\
: 05 \\
1.05 \\
1.15 \\
1.25 \\
1.35 \\
1.195 \\
1.55 \\
1.65 \\
1.75 \\
1.05 \\
1.95 \\
2.05 \\
2.15 \\
2.25 \\
2.35 \\
2.45 \\
2.55 \\
2.65 \\
2.75 \\
2.85\end{array}$ & 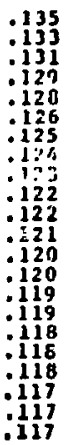 & $\begin{array}{l}: 311 \\
: 350 \\
: 392 \\
: 635 \\
: 491 \\
: 330 \\
: 580 \\
: 533 \\
: 797 \\
: 746 \\
: 896 \\
: 863 \\
: 933 \\
1: 000 \\
1.069 \\
1.140 \\
1.214 \\
1.290 \\
1.368 \\
1.449 \\
1.532 \\
1.617\end{array}$ & $\begin{array}{l}: 449 \\
: 1483 \\
: 530 \\
: 573 \\
: 619 \\
: 6518 \\
: 718 \\
: 771 \\
: 527 \\
: 804 \\
: 9164 \\
1.706 \\
1.071 \\
1.133 \\
1.207 \\
1.278 \\
1.352 \\
1.428 \\
1.516 \\
1.587 \\
1.670 \\
1.755\end{array}$ & $\begin{array}{l}4.20 \\
4.14 \\
4.01 \\
3.91 \\
3.81 \\
3.74 \\
3.67 \\
3.61 \\
3.55 \\
3.51 \\
3.44 \\
3.43 \\
3.39 \\
3.34 \\
3.34 \\
3.31 \\
3.29 \\
3.27 \\
3.25 \\
3.23 \\
3.22 \\
3.20\end{array}$ & $\begin{array}{l}79.5 \\
78: 1 \\
77: 0 \\
75: 9 \\
75: 0 \\
74: 3 \\
73: 6 \\
73: 0 \\
72: 8 \\
71.9 \\
71: 5 \\
71: 1 \\
70.8 \\
70.5 \\
70.2 \\
69: 9 \\
69.7 \\
69.5 \\
69: 3 \\
69.1 \\
68.9 \\
68.8\end{array}$ & $\begin{array}{r}168.910 \\
153.515 \\
161: 498 \\
130.702 \\
120: 908 \\
112.731 \\
104: 322 \\
37.553 \\
97.171 \\
84.771 \\
79.397 \\
74: 493 \\
70.008 \\
65.899 \\
62.126 \\
58.636 \\
35.458 \\
32.506 \\
49.775 \\
67.246 \\
46.899 \\
42.718\end{array}$ \\
\hline
\end{tabular}

PAD PUEL CAPSlLE (HITH CORIUh)

90 MATTS: 6 gUR. CXL 15 MATTS

$(.50 \mathrm{D1s} \times .200 \mathrm{t} .8)$
MIE PAD DIA $=3.475$

HIN GRAPUITE DIMENS : CDGE TK : $750^{\circ}$ FACE TX $100 " 1076$ CLAD HEIGHT - .07800 FUEL (CYL CIEAR - .125"

\begin{tabular}{|c|c|c|c|c|c|c|c|c|}
\hline PAD DIA & PAD THICX & EDIT: & $\frac{\text { GRAPHI }}{\text { IXSEE }}$ & IE & INTAL PAD UEIRIIT & BAL COFP & IMPACT VEIRCITY & WATT (Th)/TOUHD \\
\hline $\begin{array}{l}3.475 \\
3.675 \\
3.875 \\
4.075 \\
4.275 \\
. .475 \\
4.675 \\
4.875 \\
5.075 \\
5.275 \\
5.475 \\
5.675 \\
5.875 \\
6.075 \\
6.275 \\
6.475 \\
6.675 \\
6.675 \\
7.075 \\
7.275 \\
7.475 \\
7.675 \\
7.075\end{array}$ & $\begin{array}{l}.668 \\
.664 \\
.660 \\
.656 \\
.653 \\
.650 \\
.648 \\
.646 \\
.644 \\
.642 \\
.641 \\
.639 \\
.638 \\
.637 \\
.636 \\
.635 \\
.634 \\
.633 \\
.632 \\
.632 \\
.631 \\
.630 \\
.630\end{array}$ & $\begin{array}{r}.75 \\
: 85 \\
: 95 \\
1.05 \\
1.15 \\
1.25 \\
1.35 \\
1.45 \\
1.55 \\
1.65 \\
1.75 \\
1.85 \\
1.95 \\
2.05 \\
2.15 \\
2.25 \\
2.35 \\
2.45 \\
2.55 \\
2.65 \\
2.75 \\
2.85 \\
2.95\end{array}$ & $\begin{array}{l}.136 \\
: 136 \\
: 132 \\
: 130 \\
: 129 \\
: 127 \\
: 126 \\
: 125 \\
: 124 \\
: 123 \\
: 123 \\
: 122 \\
: 121 \\
: 121 \\
1120 \\
: 120 \\
: 119 \\
: 119 \\
: 118 \\
: 118 \\
: 118 \\
: 117 \\
: 117\end{array}$ & $\begin{array}{l}.352 \\
: 394 \\
: 438 \\
: 484 \\
: 532 \\
.583 \\
.636 \\
.692 \\
: 749 \\
: 809 \\
.872 \\
.936 \\
1.003 \\
1.073 \\
1.144 \\
1.218 \\
1.294 \\
1.373 \\
1.453 \\
1.537 \\
1.622 \\
1.710 \\
1.001\end{array}$ & $\begin{array}{l}.519 \\
: 559 \\
: 609 \\
.649 \\
: 698 \\
.749 \\
: 802 \\
: 857 \\
: 915 \\
: 975 \\
1.037 \\
1.102 \\
1.169 \\
1.238 \\
1.310 \\
1.304 \\
1.460 \\
1.538 \\
1.619 \\
1.7192 \\
1.788 \\
1.875 \\
1.965\end{array}$ & $\begin{array}{l}4.37 \\
4.22 \\
4.99 \\
3.08 \\
3.89 \\
3.81 \\
3.73 \\
3.67 \\
3.62 \\
3.57 \\
3.52 \\
3.49 \\
3.45 \\
3.41 \\
3.38 \\
3.36 \\
3.33 \\
3.31 \\
3.29 \\
3.27 \\
3.24 \\
3.22\end{array}$ & $\begin{array}{l}80.3 \\
78.9 \\
77: 7 \\
76.7 \\
75.8 \\
75.0 \\
74.2 \\
73.8 \\
73.1 \\
72.6 \\
72.1 \\
71.7 \\
71.3 \\
71.0 \\
70.7 \\
70.4 \\
70.1 \\
69.9 \\
69.7 \\
69.5 \\
69.3 \\
69.1 \\
69.0\end{array}$ & $\begin{array}{r}173.706 \\
160.775 \\
149.071 \\
138.467 \\
128.847 \\
120.109 \\
112.158 \\
104.913 \\
98.300 \\
92.252 \\
86.713 \\
81.630 \\
76.958 \\
72.656 \\
68.699 \\
65.024 \\
61.632 \\
58.989 \\
55.571 \\
52.359 \\
50.334 \\
47.930 \\
45.793\end{array}$ \\
\hline
\end{tabular}


PAD TUEL CATSUle (UITH CURIUH)

7 FUER CYL 15 HATTS

(.50 Dia $\times .20045)$
HIN PAD DIA $=3.685$

HIA GRATIIE DIHERS :

Enci: TK: .7Sn"

FUEL HEIGHT: $: 10220$

CLAD WEIGHT .09JO

FUEL CYE CLES - . .125"

\begin{tabular}{|c|c|c|c|c|c|c|c|c|}
\hline \multirow[b]{2}{*}{ F.U DIA } & \multicolumn{4}{|c|}{ FRAPIIITE } & \multirow[b]{2}{*}{ TOTAL TAD HELGUT } & \multirow[b]{2}{*}{ BAL COEF } & \multirow[b]{2}{*}{ IUPACT VELOCITY } & \multirow[b]{2}{*}{ LATT (Th)/ POUAD } \\
\hline & PAD IUICK & ctore & ITCE & DETCII & & & & \\
\hline $\begin{array}{l}3.688 \\
3.588 \\
4.080 \\
4.288 \\
4.488 \\
4.698 \\
4.038 \\
5.088 \\
5.288 \\
5.468 \\
5.683 \\
5.888 \\
6.088 \\
5.288 \\
6.468 \\
6.688 \\
6.888 \\
7.088 \\
7.288 \\
7.488 \\
7.688 \\
7.888 \\
8.088 \\
8.288 \\
8.488 \\
8.688 \\
8.858\end{array}$ & $\begin{array}{l}.670 \\
.665 \\
.661 \\
.658 \\
.655 \\
.632 \\
.650 \\
.647 \\
.645 \\
.644 \\
.642 \\
.641 \\
.639 \\
.6338 \\
.637 \\
.636 \\
.635 \\
.634 \\
.634 \\
.633 \\
.632 \\
.632 \\
.631 \\
.630 \\
.630 \\
.629 \\
.629\end{array}$ & $\begin{array}{l}.75 \\
.85 \\
.95 \\
1.05 \\
1.15 \\
1.25 \\
1.35 \\
1.65 \\
1.55 \\
1.65 \\
1.75 \\
1.85 \\
1.95 \\
2.05 \\
2.15 \\
2.25 \\
2.35 \\
2.45 \\
2.55 \\
2.65 \\
2.75 \\
2.85 \\
2.95 \\
3.05 \\
3.15 \\
3.25 \\
3.35\end{array}$ & 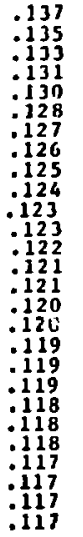 & $\begin{array}{r}.397 \\
.411 \\
.487 \\
.536 \\
.587 \\
.610 \\
.696 \\
.754 \\
.814 \\
.877 \\
.941 \\
1.098 \\
1.078 \\
1.150 \\
1.224 \\
1.300 \\
1.379 \\
1.460 \\
1.543 \\
1.628 \\
1.716 \\
1.807 \\
1.890 \\
1.994 \\
2.091 \\
2.190 \\
2.292\end{array}$ & $\begin{array}{r}.590 \\
.634 \\
.680 \\
.729 \\
.780 \\
.834 \\
.899 \\
.947 \\
1.097 \\
1.070 \\
1.135 \\
1.202 \\
1.271 \\
1.363 \\
1.417 \\
1.493 \\
1.572 \\
1.653 \\
1.736 \\
1.822 \\
1.910 \\
2.007 \\
2.092 \\
2.187 \\
2.284 \\
2.384 \\
2.485\end{array}$ & $\begin{array}{l}4.12 \\
4.27 \\
4.14 \\
4.04 \\
3.94 \\
3.16 \\
3.79 \\
3.72 \\
3.67 \\
3.7 .1 \\
3.57 \\
3.53 \\
3.49 \\
3.44 \\
3.42 \\
3.40 \\
3.37 \\
3.35 \\
3.33 \\
3.30 \\
3.29 \\
3.27 \\
3.25 \\
3.24 \\
3.22 \\
3.21 \\
3.20\end{array}$ & $\begin{array}{l}80.7 \\
79.4 \\
78.2 \\
77.2 \\
79.3 \\
75.5 \\
74.8 \\
74.1 \\
73.6 \\
73.0 \\
72.6 \\
72.2 \\
71.8 \\
71.4 \\
71.1 \\
30.8 \\
70.5 \\
70.3 \\
70.1 \\
69.8 \\
69.7 \\
69.5 \\
69.3 \\
69.1 \\
69.0 \\
60.9 \\
68.7\end{array}$ & $\begin{array}{l}177.871 \\
165.487 \\
354.197 \\
143.898 \\
134.493 \\
125.895 \\
118.026 \\
110.813 \\
174.192 \\
98.107 \\
92.505 \\
87.341 \\
82.573 \\
78.164 \\
74.001 \\
70.295 \\
66.779 \\
63.509 \\
60.464 \\
57.624 \\
54.973 \\
52.494 \\
50.173 \\
47.998 \\
45.958 \\
44.041 \\
42.238\end{array}$ \\
\hline
\end{tabular}

PAD PUEL CAPSLLE (WITH CURIUH)

8 FUEL CYL 15 HATTS

$(.50 \mathrm{DLa} \times .200 \mathrm{LE})$
MIN TAD DIA -3.904

HIN TRAPHITE DIMENS : EDCE TK : ?50"

FUEL WEICIT : $\$ 1168$

(.020Thtck)

FUEI. CYL CLEAR - .125"

\begin{tabular}{|c|c|c|c|c|c|c|c|c|}
\hline PAD DIA & PAD THICX & BDHE & $\frac{\text { GRAPHI }}{\text { YACL }}$ & E & IERAL PAD VEICIIT & BAL COEP & IHPACT VEIOCITY & WATT (Th)/POUND \\
\hline $\begin{array}{l}3.904 \\
4.104 \\
4.304 \\
4.504 \\
4.704 \\
4.904 \\
5.104 \\
5.304 \\
5.504 \\
5.704 \\
5.904 \\
6.104 \\
6.304 \\
6.504 \\
6.704 \\
6.904 \\
7.194 \\
7.304 \\
7.504 \\
7.704 \\
7.904 \\
6.104 \\
8.104\end{array}$ & $\begin{array}{l}.671 \\
.666 \\
.663 \\
.659 \\
.656 \\
.653 \\
.651 \\
.649 \\
.647 \\
.645 \\
.643 \\
.642 \\
.641 \\
.639 \\
.638 \\
.637 \\
.636 \\
.635 \\
.635 \\
.634 \\
.633 \\
.633 \\
.632\end{array}$ & $\begin{array}{l}.75 \\
.85 \\
.95 \\
1.05 \\
1.15 \\
1.25 \\
1.35 \\
1.45 \\
1.55 \\
1.65 \\
1.75 \\
1.85 \\
1.95 \\
2.05 \\
2.15 \\
2.25 \\
2.35 .2 \\
2.45 \\
2.55 \\
2.65 \\
2.75 \\
2.85 \\
2.95\end{array}$ & $\begin{array}{l}.138 \\
: 135 \\
1134 \\
1132 \\
1130 \\
1129 \\
1128 \\
1127 \\
1126 \\
1125 \\
: 124 \\
: 123 \\
: 123 \\
1122 \\
1121 \\
: 121 \\
: 120 \\
: 120 \\
: 120 \\
: 119 \\
: 119 \\
1119 \\
1110\end{array}$ & $\begin{array}{l}.444 \\
.491 \\
.540 \\
.591 \\
.645 \\
.701 \\
.759 \\
.819 \\
.882 \\
.947 \\
1.014 \\
1.084 \\
1.156 \\
1.230 \\
1.307 \\
1.396 \\
1.467 \\
1.550 \\
1.636 \\
1.724 \\
1.815 \\
1.907 \\
2.002\end{array}$ & $\begin{array}{l}.665 \\
.712 \\
.761 \\
.812 \\
.866 \\
.922 \\
.980 \\
1.040 \\
1.103 \\
1.168 \\
1.235 \\
1.305 \\
1.377 \\
1.451 \\
1.528 \\
1.605 \\
1.678 \\
1.771 \\
1.857 \\
1.945 \\
2.035 \\
2.128 \\
2.223\end{array}$ & $\begin{array}{l}4.44 \\
4.30 \\
4.18 \\
4.08 \\
3.98 \\
3.90 \\
3.83 \\
3.76 \\
3.70 \\
3.65 \\
3.61 \\
3.56 \\
3.53 \\
3.49 \\
3.45 \\
3.43 \\
3.40 \\
3.38 \\
3.35 \\
3.13 \\
3.31 \\
3.30 \\
3.30\end{array}$ & $\begin{array}{l}81.0 \\
79.7 \\
78.6 \\
17.6 \\
76.7 \\
75.9 \\
75.2 \\
74.5 \\
73.9 \\
73.4 \\
73.0 \\
72.5 \\
72.1 \\
71.8 \\
71.4 \\
71.1 \\
70.9 \\
70.6 \\
79.4 \\
70.1 \\
69.9 \\
69.8 \\
69.6\end{array}$ & $\begin{array}{r}180.263 \\
168.427 \\
157.592 \\
147.651 \\
138.524 \\
130.135 \\
122.417 \\
115.309 \\
108.754 \\
102.701 \\
97.106 \\
91.926 \\
87.125 \\
82.669 \\
78.528 \\
71.075 \\
71.085 \\
67.735 \\
64.607 \\
61.682 \\
58.943 \\
51.376 \\
53.967\end{array}$ \\
\hline
\end{tabular}


Pad Fuel carste (hitu cuRtuh)

9 fuel crl 13 watts

(.50 D1. $=.200 \mathrm{LS})$
MR FAD DIA $=4.121$

MIN TRAPIITE DIMENS : EDGE $T K=.750 "$

FUEL VEIGUT :- 1314

FuEi CrL CLEAR - .125"

\begin{tabular}{|c|c|c|c|c|c|c|c|c|}
\hline PAD DIA & PAD TUICK & EIB:E & $\frac{\text { CPARU }}{\text { IXCE }}$ & IE & TOTAL PAD UEIAUI & BA. COEF & IHPACT VELOCITY & $\operatorname{HaTt}(T h) /$ rousd \\
\hline $\begin{array}{l}4.121 \\
4.321 \\
4.521 \\
4.721 \\
4.921 \\
5.1121 \\
5.321 \\
5.521 \\
5.721 \\
5.921 \\
6.121 \\
6.521 \\
6.521 \\
6.721 \\
6.921 \\
7.121 \\
7.321 \\
7.521 \\
7.721 \\
7.921 \\
8.121 \\
0.321 \\
0.521\end{array}$ & $\begin{array}{l}.671 \\
.667 \\
.663 \\
.660 \\
.657 \\
.654 \\
.652 \\
.659 \\
.648 \\
.646 \\
.644 \\
.643 \\
.642 \\
.640 \\
.639 \\
.639 \\
.637 \\
.636 \\
.636 \\
.635 \\
.634 \\
.633 \\
.633\end{array}$ & $\begin{array}{l}.75 \\
.85 \\
1.95 \\
1.05 \\
1.15 \\
1.25 \\
1.35 \\
1.45 \\
1.55 \\
1.65 \\
1.75 \\
1.85 \\
1.95 \\
2.05 \\
2.15 \\
2.25 \\
2.35 \\
2.45 \\
2.55 \\
2.55 \\
2.75 \\
2.85 \\
2.95\end{array}$ & $\begin{array}{l}.138 \\
1136 \\
11 \\
1134 \\
1132 \\
1131 \\
1129 \\
1128 \\
1127 \\
1126 \\
1125 \\
1124 \\
1124 \\
1123 \\
1122 \\
1122 \\
1121 \\
.121 \\
.120 \\
1120 \\
.120 \\
1119 \\
1119 \\
1119 \\
1119\end{array}$ & $\begin{array}{l}.495 \\
.545 \\
.596 \\
.050 \\
.706 \\
.765 \\
.625 \\
.889 \\
.953 \\
1.021 \\
1.091 \\
1.163 \\
1.237 \\
1.314 \\
1.393 \\
1.475 \\
1.559 \\
1.644 \\
1.733 \\
1.823 \\
1.916 \\
2.011 \\
2.109\end{array}$ & $\begin{array}{l}.744 \\
.793 \\
.845 \\
.898 \\
.955 \\
1.011 \\
1.774 \\
1.137 \\
1.202 \\
1.21 .7 \\
1.719 \\
1.411 \\
1.886 \\
1.563 \\
1.642 \\
1.723 \\
1.807 \\
1.1703 \\
1.981 \\
2.072 \\
2.165 \\
2.260 \\
2.357\end{array}$ & $\begin{array}{l}4.46 \\
4.32 \\
4.21 \\
4.10 \\
4.71 \\
3.93 \\
3.7 .76 \\
3.79 \\
3.74 \\
3.7 .8 \\
3.64 \\
3.58 \\
3.55 \\
3.52 \\
3.49 \\
3.46 \\
3.43 \\
3.45 \\
3.38 \\
3.36 \\
3.34 \\
3.32 \\
3.30\end{array}$ & $\begin{array}{l}81.1 \\
79.9 \\
78.8 \\
77.8 \\
76.9 \\
76.2 \\
75.5 \\
74.8 \\
74.3 \\
73.7 \\
73.3 \\
72.8 \\
72.4 \\
72.1 \\
71.7 \\
71.4 \\
71.1 \\
70.5 \\
70.6 \\
70.4 \\
70.2 \\
70.0 \\
69.8\end{array}$ & $\begin{array}{l}181.368 \\
179.112 \\
159.710 \\
150.178 \\
141.357 \\
133.213 \\
125.988 \\
113.728 \\
112.283 \\
196.309 \\
100.765 \\
95.615 \\
90.824 \\
86.364 \\
82.205 \\
78.324 \\
74.177 \\
71.304 \\
68.126 \\
65.147 \\
62.351 \\
59.724 \\
57.253\end{array}$ \\
\hline
\end{tabular}

PAD ruet catsule (HTth curtui)

150 WATrS:

10 FUEL CYL 13 wATIS

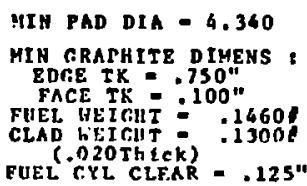

PAD DIA

\begin{abstract}
PAD THICX
\end{abstract}

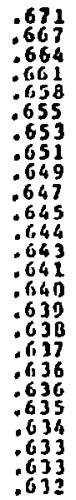

GRAPHIT:

$+360$

540
6.740

5.94 .5

5.340

5.540

5.740

6.140

6.340
6.540

6.540
6.740

6.940

7.940

7.540

7.740

8.140

8. 340

8.740

8.940

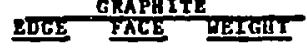

$\begin{array}{lll}.75 & .138 & .549\end{array}$

$\begin{array}{rrr}.85 & 0136 & .601 \\ .95 & .134 & .655 \\ .05 & .133 & .712\end{array}$

$1.05 \quad: 133$

$\begin{array}{lll}1.25 & .130 & .831\end{array}$

$1.35 \quad: 129 \quad 0894$

$\begin{array}{lll}1.45 & 0128 & .060 \\ 1.55 & .127 & 1.008\end{array}$

$1.65 \quad .126 \quad 1: 098$

$1.75 \quad: 125 \quad 1.170$

$\begin{array}{lll}1.95 & .124 & 1.245 \\ 1.95 & .124 & 1.322\end{array}$

$\begin{array}{lll}2.05 & 0123 & 1.401\end{array}$

$2.25 \quad .122 \quad 1.567$

$\begin{array}{lll}2.35 & 0121 & 1.653 \\ 2.155 & 122 & 1.742\end{array}$

$2.55 \quad .120 \quad 1.833$

$2.65 \quad: 120 \quad \frac{1}{2.926}$

$2.85 \quad .119 \quad 2.119$

2.95
3.119

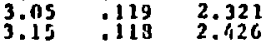

(.50 D1A $\times .200 \mathrm{Lg})$

TOTAI. PAD WE IGIIT

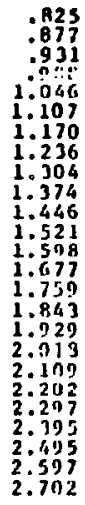

BAL COEF

4.46
4.33
4.22

4.

3.25

3.78

3.82

3.76

3.66
3.62

3.58

3.51

3.45

3.43

3.40

3.36

3. 34

3.21
IMPACT VELOCITY

31.1
$80: 0$
$78: 0$
$77: 0$
$77: 1$
$76: 4$
75.7
$75: 1$
74.5
$74: 0$
$73: 5$
$73: 1$
$72: 7$
72.3
72.0
$71: 7$
$71: 4$
$71: 1$
$70: 9$
$70: 6$
$70: 4$
$70: 2$
70.0
69.9
69.7

WATT $(T h) /$ POWD

181.613 167.976 151.794 135.2909 128.098 121.310 115.003 109.137
303.675 98.584 93.835 85.252 71.734 $74: 324$

71.122

68.114

65.294 60..107 57.738 55.501 
rad rUEt CarSULE (UITU CHREUH)

12 FUEL CTL 15 WATtS

(.50 DIs $\times .200 \mathrm{Ls})$

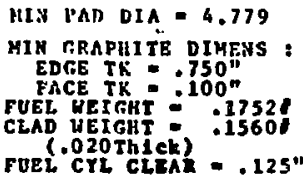

\begin{tabular}{|c|c|c|c|c|c|c|c|c|}
\hline \multirow[b]{2}{*}{ PAD DIA } & \multicolumn{4}{|c|}{ NRATIITE. } & \multirow[b]{2}{*}{ TOTAL FAD HETGUT } & \multirow[b]{2}{*}{ BAL COEF } & \multirow[b]{2}{*}{ IHPACT velocir } & \multirow[b]{2}{*}{ USTI (Th)/POUSD } \\
\hline & PAD THICE & EDCE & TKCE & PLTHE & & & & \\
\hline $\begin{array}{l}4.779 \\
4.979 \\
5.379 \\
5.379 \\
5.579 \\
5.779 \\
5.979 \\
6.179 \\
6.379 \\
6.579 \\
0.779 \\
6.979 \\
7.179 \\
7.379 \\
7.579 \\
7.779 \\
7.979 \\
8.179 \\
8.379 \\
8.579 \\
8.779 \\
8.979 \\
9.179 \\
9.379 \\
9.579 \\
.779 \\
9.979\end{array}$ & $\begin{array}{l}.671 \\
.667 \\
.664 \\
.661 \\
.658 \\
.656 \\
.654 \\
.652 \\
.650 \\
.648 \\
.647 \\
.645 \\
.644 \\
.643 \\
.641 \\
.640 \\
.639 \\
.638 \\
.638 \\
.637 \\
.636 \\
.635 \\
.635 \\
.634 \\
.633 \\
.633 \\
.632\end{array}$ & $\begin{array}{r}.75 \\
.85 \\
1.95 \\
1.05 \\
1.15 \\
1.25 \\
1.35 \\
1.45 \\
1.35 \\
1.65 \\
1.75 \\
1.85 \\
3.95 \\
2.05 \\
2.15 \\
2.25 \\
2.35 \\
2.45 \\
2.55 \\
2.65 \\
2.75 \\
2.85 \\
2.95 \\
3.05 \\
3.15 \\
3.25 \\
3.35\end{array}$ & 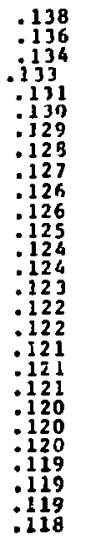 & $\begin{array}{r}.666 \\
.723 \\
.783 \\
.844 \\
.948 \\
.974 \\
1.042 \\
1.113 \\
1.186 \\
1.261 \\
1.333 \\
1.418 \\
1.509 \\
1.585 \\
1.672 \\
1.761 \\
1.052 \\
1.946 \\
2.042 \\
2.140 \\
2.240 \\
2.343 \\
2.448 \\
2.556 \\
2.666 \\
2.778 \\
2.892\end{array}$ & $\begin{array}{r}.998 \\
1.055 \\
1.114 \\
1.175 \\
1.237 \\
1.375 \\
1.373 \\
1.414 \\
1.517 \\
1.592 \\
1.670 \\
1.749 \\
1.832 \\
1.016 \\
2.003 \\
2.092 \\
2.163 \\
2.277 \\
2.373 \\
2.471 \\
2.572 \\
2.674 \\
2.780 \\
2.837 \\
2.997 \\
3.109 \\
3.223\end{array}$ & $\begin{array}{r}4.15 \\
4.33 \\
4.23 \\
4.33 \\
4.75 \\
3.08 \\
3.91 \\
3.85 \\
3.79 \\
3.78 \\
3.70 \\
3.65 \\
3.62 \\
3.58 \\
3.55 \\
3.52 \\
3.49 \\
3.46 \\
3.44 \\
3.42 \\
3.39 \\
3.37 \\
3.36 \\
3.34 \\
3.32 \\
3.33 \\
3.29\end{array}$ & $\begin{array}{r}81.0 \\
79.9 \\
79.0 \\
78.10 \\
77.3 \\
76.6 \\
76.0 \\
75.4 \\
74.8 \\
74.3 \\
73.9 \\
73.4 \\
73.1 \\
72.7 \\
72.4 \\
72.0 \\
71.8 \\
71.5 \\
71.2 \\
71.0 \\
70.8 \\
70.6 \\
70.4 \\
70.2 \\
70.0 \\
69.9 \\
69.7\end{array}$ & $\begin{array}{r}180.344 \\
170.613 \\
161.546 \\
153.100 \\
145.224 \\
137.876 \\
131.017 \\
124.611 \\
118.622 \\
113.019 \\
107.773 \\
102.857 \\
98.246 \\
93.918 \\
89.852 \\
86.029 \\
82.430 \\
79.041 \\
75.645 \\
72.829 \\
69.982 \\
67.290 \\
64.764 \\
62.334 \\
60.031 \\
57.885 \\
55.831\end{array}$ \\
\hline
\end{tabular}

PAD FUEL CARSUE (WITH CHEIYM)

14 FUEL CYL 15 WATTS

(.50 Dla $\times .200 \mathrm{LB}$ )
GRAPHITE

PAD DIA PAD THICK EDGE FACE WETGITE TOTAL PAD WETEIII

$\begin{array}{ll}5.222 & .670 \\ 5.422 & .667 \\ 5.622 & .664 \\ 5.822 & .661 \\ 6.022 & .658 \\ 6.222 & .656 \\ 6.422 & .654 \\ 6.622 & .652 \\ 6.822 & .650 \\ 7.022 & .649 \\ 7.222 & .647 \\ 7.422 & .646 \\ 7.622 & .645 \\ 7.822 & .643 \\ 8.022 & .642 \\ 8.222 & .641 \\ 8.422 & .640 \\ 8.622 & .639 \\ 8.822 & .638 \\ 9.022 & .638 \\ 9.222 & .637 \\ 9.422 & .636 \\ 9.622 & .636 \\ 9.822 & .635\end{array}$

$\begin{array}{ll}.75 & : 137 \\ : 85 & 136 \\ : 95 & 134 \\ 1.05 & : 133 \\ 1.15 & : 131 \\ 1.25 & : 130 \\ 1.35 & : 129 \\ 1.45 & 128 \\ 1.55 & : 127 \\ 1.65 & : 127 \\ 1.75 & : 126 \\ 1.85 & : 125 \\ 1.95 & 125 \\ 2.05 & : 124 \\ 2.15 & : 123 \\ 2.25 & : 123 \\ 2.35 & : 122 \\ 2.45 & : 122 \\ 2.55 & 121 \\ 2.65 & : 121 \\ 2.75 & : 121 \\ 2.85 & 120 \\ 2.95 & : 120 \\ 3.05 & : 120\end{array}$

.796

.858

.989
1.058

1.120

1.278
1.356

1. 356

1. 519

1.604
1.602

1.781

1.873

2.064

2.162

2. 264

2.473

2.5131

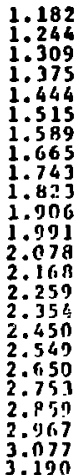

DA. COBP

4.41

4. 31

4.21

4.05
3.98

3.98

3.86

3.86

3.72

3.72

3.64

3.60
3.57
3.56

3.54

3.51

3.46

3.44

3.40

3.: 36
HIN PAD DIA -5.222

MIR GRATHITE DIMENS : EDGE TK $=.750^{\circ}$

FUEL HEICIT: 2044 .1820 PUEL CYL CLEAR - 125 "

IMPACT VELOCITY HATT(Th)/POUSD

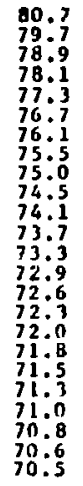

177.571

160.421

152.650

245.368

132.132

126.118

120.469

110.164

105.463

101.0 .15

96.860
92.922

92.922

85.693

82.372

76.255

73.436

70.763

68.226 
PAD TUEL CAFSULE (HITH CUHIUH)

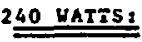

16 FUEL CYL 15 WATTS

(.50 D1a $\times .20025)$

\begin{tabular}{ll} 
JAD DIA & PAD TUICE \\
\hline 5.663 & .669 \\
5.863 & .666 \\
6.063 & .66 .3 \\
6.263 & .660 \\
6.463 & .653 \\
6.663 & .656 \\
6.863 & .654 \\
7.063 & .652 \\
7.263 & .651 \\
7.463 & .649 \\
7.663 & .649 \\
7.863 & .646 \\
8.063 & .645 \\
8.263 & .644 \\
8.463 & .643 \\
6.663 & .642 \\
8.863 & .641 \\
9.363 & .640 \\
9.263 & .639 \\
9.463 & .638 \\
9.663 & .638 \\
9.863 & .637
\end{tabular}

270 Wigrs:

\begin{tabular}{|c|c|c|}
\hline$E \sqrt{+E}$ & $\frac{\text { rRAPII }}{\text { TKCLE }}$ & TE \\
\hline $\begin{array}{l}.75 \\
.85 \\
.95 \\
1.05 \\
1.15 \\
1.25 \\
1.35 \\
1.45 \\
1.55 \\
1.05 \\
1.75 \\
1.85 \\
1.95 \\
2.05 \\
2.15 \\
2.25 \\
2.35 \\
2.45 \\
2.55 \\
2.65 \\
2.75 \\
2.85\end{array}$ & 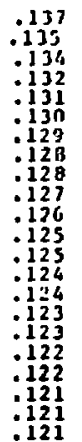 & $\begin{array}{l}.936 \\
1.003 \\
1.072 \\
1.164 \\
1.210 \\
1.294 \\
1.373 \\
1.454 \\
1.537 \\
1.623 \\
1.711 \\
1.801 \\
1.993 \\
1.968 \\
2.085 \\
2.184 \\
2.286 \\
2.390 \\
2.496 \\
2.604 \\
2.715 \\
2.828\end{array}$ \\
\hline
\end{tabular}

\begin{tabular}{|c|}
\hline $\begin{array}{l}1.377 \\
1.1915 \\
1.514 \\
3.596 \\
1.660 \\
1.733 \\
1.515 \\
1.896 \\
1.979 \\
2.064 \\
2.152 \\
2.242 \\
2.335 \\
2.820 \\
2.526 \\
2.626 \\
2.727 \\
2.831 \\
2.937 \\
3.046 \\
3.157 \\
3.270\end{array}$ \\
\hline
\end{tabular}

PAd Fuel carsile (WTta cUntur)

18 FUEL CYL 15 HATTS

$\left(.50010 \times .200 L_{5}\right)$

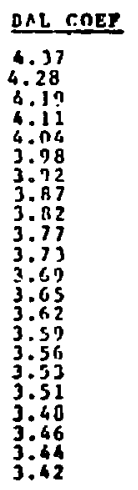

.37
.28
.17
.11
.94
.98
.72
.87
.72
.77
.69
.65
.62
.59
.56
.53
.51
.40
.46
.44
.42
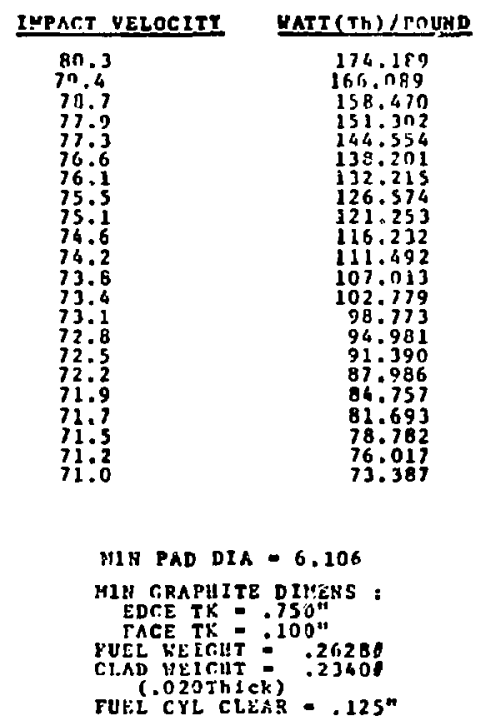

\begin{tabular}{ll} 
PAD DIA & PAD IHICK \\
\hline 6.106 & .667 \\
6.306 & $: 664$ \\
6.506 & .662 \\
6.706 & .660 \\
6.906 & .658 \\
7.106 & .656 \\
7.366 & .654 \\
7.506 & .652 \\
7.706 & .651 \\
7.906 & .649 \\
8.265 & .648 \\
8.306 & .647 \\
8.506 & .645 \\
8.706 & .644 \\
8.906 & .643 \\
9.106 & .642 \\
9.306 & .641 \\
9.506 & .640 \\
9.706 & .640 \\
9.906 & .639
\end{tabular}

\begin{tabular}{|c|c|}
\hline EECHE & $\frac{G \pi s p h}{F K C}$ \\
\hline $\begin{array}{r}.75 \\
085 \\
095 \\
2.05 \\
1.15 \\
1.25 \\
1.35 \\
1.45 \\
1.55 \\
1.65 \\
1.75 \\
3.85 \\
1.95 \\
2.05 \\
2.15 \\
2.25 \\
2.35 \\
2.45 \\
2.35\end{array}$ & $\begin{array}{l}1136 \\
1134 \\
1133 \\
1132 \\
1131 \\
1130 \\
1129 \\
1128 \\
1128 \\
1127 \\
1126 \\
1126 \\
1125 \\
1124 \\
1124 \\
1123 \\
1123 \\
1122 \\
1122 \\
1122\end{array}$ \\
\hline
\end{tabular}

GRAPHITE

\begin{tabular}{|c|c|}
\hline entalle & ENTAL PAD HELOIIT \\
\hline $\begin{array}{l}1.088 \\
1.160 \\
1.235 \\
1.312 \\
1.391 \\
1.472 \\
1.556 \\
1.642 \\
1.731 \\
1.821 \\
1.914 \\
2.809 \\
2.107 \\
2.207 \\
2.3009 \\
2.413 \\
2.520 \\
2.629 \\
2.741 \\
2.854\end{array}$ & $\begin{array}{l}1.585 \\
1.657 \\
1.732 \\
1.807 \\
1.998 \\
1.969 \\
2.053 \\
2.939 \\
2.227 \\
2.319 \\
2.411 \\
2.506 \\
2.604 \\
2.704 \\
2.806 \\
2.910 \\
3.017 \\
3.126 \\
3.237 \\
3.351\end{array}$ \\
\hline
\end{tabular}

BAL COEF
4.33
4.24
4.16
4.87
4.03
3.27
3.91
3.86
3.82
3.77
3.73
3.70
3.66
3.63
3.60
3.57
3.54
3.52
3.50
3.47

PAD rUEL CAFSUTE (HITII CUHIUM)

J00 HATTS:

MIN PAD DIA - 5.563

HIN CRAFHITE DINEHS: EDGE TK $=.750^{\circ}$

FUEL HFITHT: $: 2336 \mathrm{P}$ CLAO UE YGIIT: :2080 FUEL Crithiek) - ciEAR - .125"

$\begin{array}{ll}80.3 & 174.189 \\ 7 n .4 & 165.089 \\ 70.7 & 158.470 \\ 77.9 & 151.302 \\ 77.3 & 244.554 \\ 76.6 & 138.201 \\ 76.1 & 132.213 \\ 75.5 & 126.574 \\ 75.1 & 121.253 \\ 74.6 & 116.232 \\ 74.2 & 111.492 \\ 73.8 & 107.013 \\ 73.4 & 102.779 \\ 73.1 & 98.773 \\ 72.8 & 94.981 \\ 72.5 & 91.390 \\ 72.2 & 87.986 \\ 71.9 & 86.757 \\ 71.7 & 81.693 \\ 71.5 & 78.782 \\ 71.2 & 76.017 \\ 71.0 & 73.387\end{array}$

\begin{tabular}{|c|c|}
\hline IYPACt VEIOCITY & HATT (Th) /PNOND \\
\hline $\begin{array}{l}79.9 \\
79.1 \\
78.4 \\
77.7 \\
77.1 \\
76.5 \\
76.0 \\
75.5 \\
75.1 \\
74.6 \\
74.2 \\
73.9 \\
73.5 \\
73.2 \\
72.9 \\
72.6 \\
72.3 \\
72.1 \\
71.8 \\
71.6\end{array}$ & $\begin{array}{r}170.325 \\
162.892 \\
155.875 \\
140.249 \\
142.990 \\
137.076 \\
131.485 \\
126.198 \\
121.192 \\
116.454 \\
111.965 \\
107.711 \\
103.677 \\
99.849 \\
96.215 \\
92.762 \\
89.480 \\
86.359 \\
83.389 \\
80.561\end{array}$ \\
\hline
\end{tabular}

20 FUEI CYL 15 MATTS

$(.50 \mathrm{D1} \times .200 \mathrm{LE})$

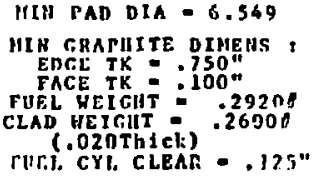

rur.j. CYI. CLEAR - .125"

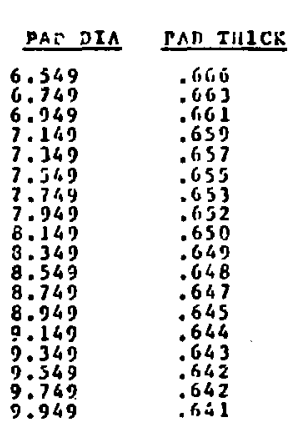

\begin{tabular}{|c|c|c|}
\hline \multirow{2}{*}{\multicolumn{3}{|c|}{ CrAniilTI: }} \\
\hline IDOP & & \\
\hline $\begin{array}{l}.75 \\
.85 \\
.75 \\
1.05 \\
1.15 \\
1.25 \\
1.35 \\
1.45 \\
1.55 \\
1.65 \\
1.75 \\
1.85 \\
1.95 \\
2.05 \\
2.15 \\
2.25 \\
2.35 \\
2.45\end{array}$ & $\begin{array}{l}1135 \\
1134 \\
11 \\
1133 \\
1132 \\
1131 \\
1130 \\
1129 \\
: 122 \\
: 127 \\
1127 \\
1126 \\
1126 \\
1125 \\
1125 \\
1124 \\
1124 \\
1123 \\
1123 \\
1123\end{array}$ & $\begin{array}{l}1.252 \\
1.329 \\
1.409 \\
1.491 \\
1.575 \\
1.662 \\
1.751 \\
1.842 \\
1.936 \\
2.031 \\
2.129 \\
2.230 \\
2.332 \\
2.437 \\
2.545 \\
2.654 \\
2.766 \\
2.880\end{array}$ \\
\hline
\end{tabular}

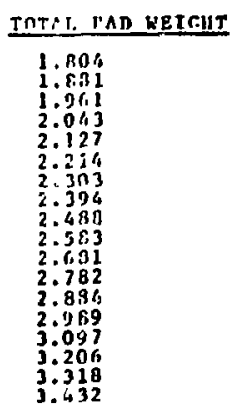

BA1. COFE
4.26
4.25
4.13
4.07
4.01
3.95
3.97
3.115
3.41
3.77
3.73
3.70
3.66
3.63
3.65
3.58
3.55
3.53

\begin{tabular}{c} 
IHPACT VEROCITT \\
\hline 79.5 \\
78.8 \\
73.1 \\
77.5 \\
76.9 \\
76.4 \\
75.9 \\
75.4 \\
75.0 \\
74.6 \\
74.2 \\
73.9 \\
73.5 \\
73.2 \\
72.9 \\
72.7 \\
72.4 \\
72.2
\end{tabular}

WATt $(T h) /$ round

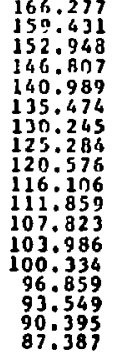


PAD IMPACT TEST COMPONENT DRAWINGS

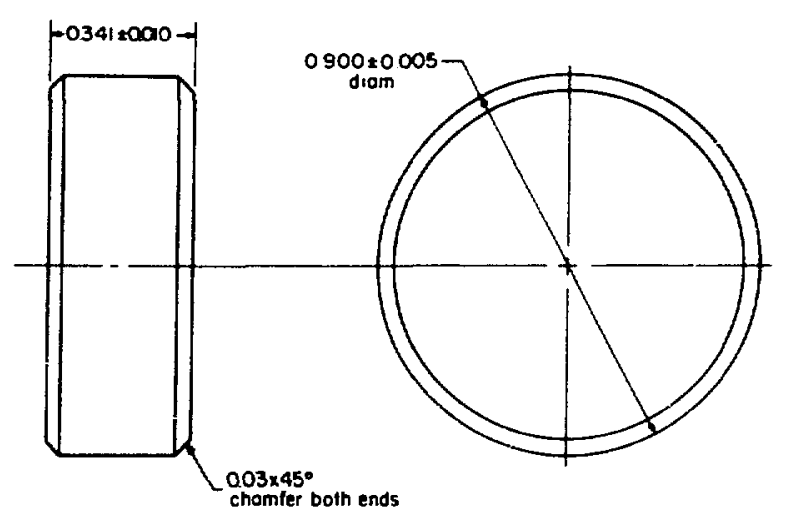

1. Moterial $\cdot \mathrm{UO}_{2}-90-95 \%$ TD

2 Inspect ond record diam and length

3. Record might to neorest 0.001

4. Rodiograph

5. Bog and lop-serialize P/N CM85-106-XXX SK-CMB5 - 106

\section{Impaci Fuel Simulant Cylinder}

\section{$7-0.020 \pm 0.001$ \\ Flof $[0.001$}

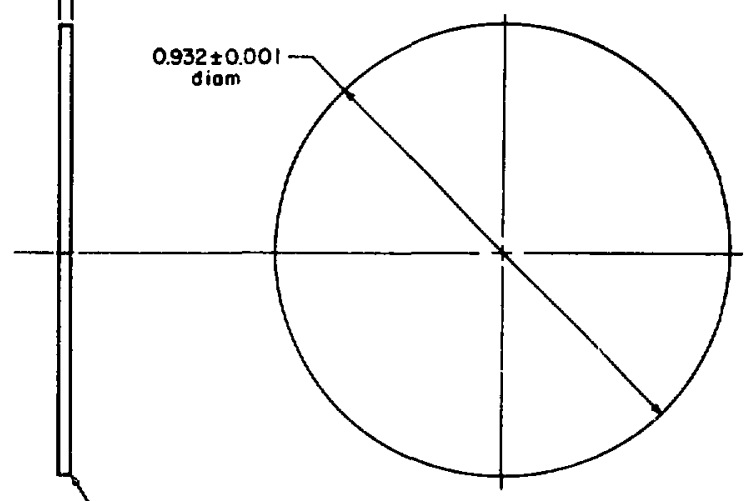

Broak all sharp corners

I. Material : $\mathrm{Pt}-25$ Ir fully annealed

2. 32 finish oll over

3. Inapact and record diam and thickness

4. Record woight to nearest $0.001 \mathrm{~g}$

5. Sondblast P/N CMBS-107-XXX

$$
\text { SK-CMB5-107 }
$$

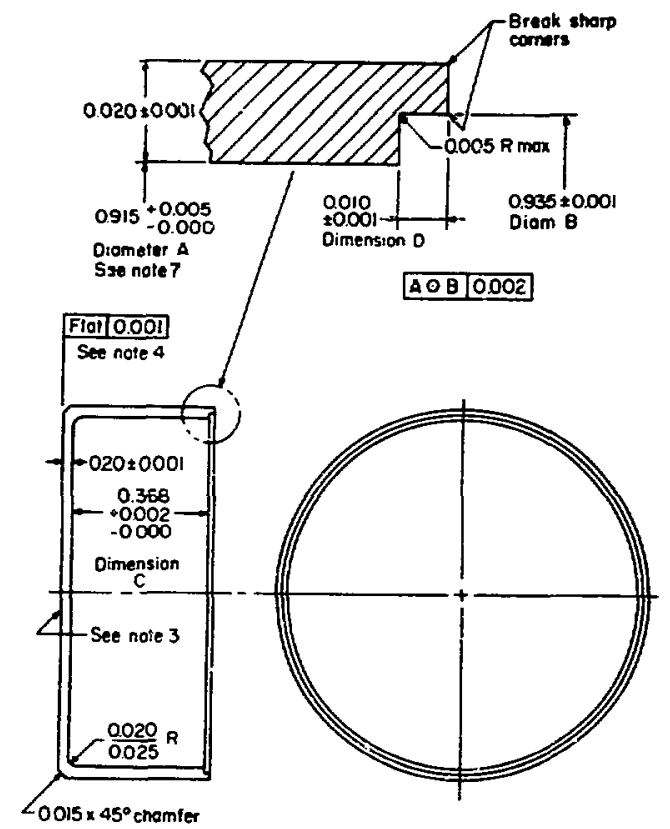

1. Adoterial PI-25 If fully onnealed 2. Moke from P/N CMBS-109

3. Sandbiant PN CMBS-108-XXX

4 Inspect ond record dimensions $A, B, C$ and $D$ and moll thickness and flatness

5.Record weight to nearesi 0.0019

6. 32. finsh oll over

7. Diometer A circular 10 within 0002 TIR

SK-CMB5-108

Impact Container

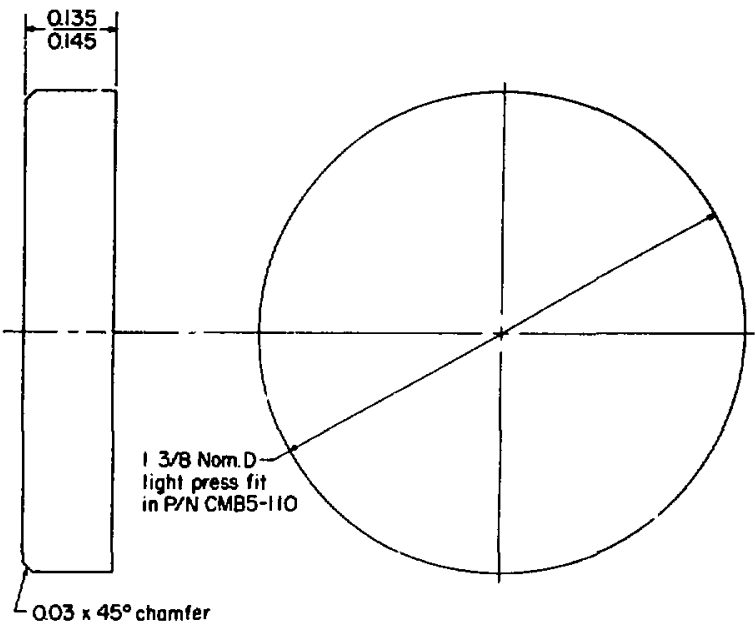

I. Materiol : grophite ( 0 be determined)

2. Inspect ond record thicknoss SK-CMB5-IO9 


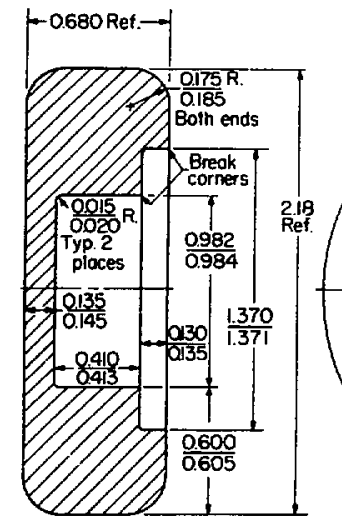

Section A-A

1. Materiol : Graphite (to be determıned)

2. Inspect and record oll wall thickness

SK-CMBS-11O

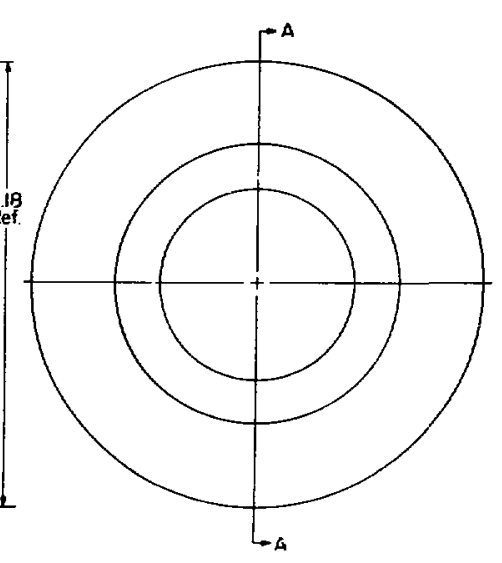

Impact Sbell

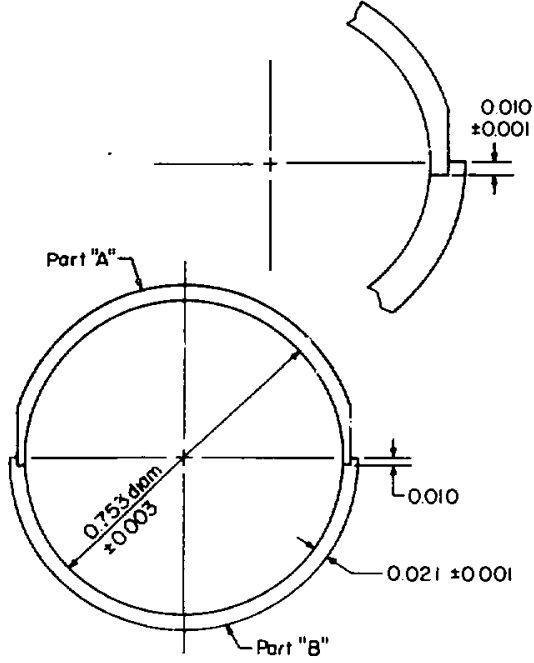

Inspection report

Weight, wall thickness, and pole height

Sandbiost P/N CMB-5-II3-A-OOI, etc

Sondbiost P/N CMB-5-113-B-OOI, etc

Moterial Pi-25 Ir fully anneoled

SK-CHB-5-113

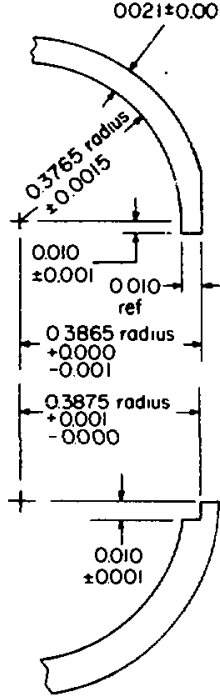

Fuel Impact Sphere Containers 